\title{
The Marine Isotope Stage 19 in the mid-latitude North Atlantic Ocean: astronomical signature and intra-interglacial variability
}

\author{
Patrizia Ferretti ${ }^{a, *}$, Simon J. Crowhurst ${ }^{b}$, B. David A. Naafs ${ }^{\text {, }}$, Carlo Barbante ${ }^{\text {a, d }}$ \\ a Consiglio Nazionale delle Ricerche, Istituto per la Dinamica dei Processi Ambientali (CNR-IDPA), Calle Larga Santa Marta 2137, Venice I-30123, Italy \\ ${ }^{\mathrm{b}}$ The Godwin Laboratory for Palaeoclimate Research, Department of Earth Sciences, University of Cambridge, Downing Street, Cambridge CB2 3EQ \\ United Kingdom \\ c Organic Geochemistry Unit, School of Chemistry and Cabot Institute, University of Bristol, Cantock's Close, BS8 1TS Bristol, United Kingdom \\ d Dipartimento di Scienze Ambientali, Informatica e Statistica, Università di Venezia, Calle Larga S. Marta 2137, Venice I-30123, Italy
}

\section{A R T I C L E I N F O}

\section{Article history:}

Received 21 March 2014

Received in revised form

21 October 2014

Accepted 24 October 2014

Available online

\section{Keywords:}

North Atlantic

Pleistocene

Precession

Insolation

Foraminifera

Stable isotopes

Oxygen isotope stratigraphy

IODP Site U1313

\begin{abstract}
A B S T R A C T
Since the seminal work by Hays et al. (1976), a plethora of studies has demonstrated a correlation between orbital variations and climatic change. However, information on how changes in orbital boundary conditions affected the frequency and amplitude of millennial-scale climate variability is still fragmentary. The Marine Isotope Stage (MIS) 19, an interglacial centred at around $785 \mathrm{ka}$, provides an opportunity to pursue this question and test the hypothesis that the long-term processes set up the boundary conditions within which the short-term processes operate. Similarly to the current interglacial, MIS 19 is characterised by a minimum of the 400-kyr eccentricity cycle, subdued amplitude of precessional changes, and small amplitude variations in insolation. Here we examine the record of climatic conditions during MIS 19 using high-resolution stable isotope records from benthic and planktonic foraminifera from a sedimentary sequence in the North Atlantic (Integrated Ocean Drilling Program Expedition 306, Site U1313) in order to assess the stability and duration of this interglacial, and evaluate the climate system's response in the millennial band to known orbitally induced insolation changes. Benthic and planktonic foraminiferal $\delta^{18} \mathrm{O}$ values indicate relatively stable conditions during the peak warmth of MIS 19 , but sea-surface and deep-water reconstructions start diverging during the transition towards the glacial MIS 18, when large, cold excursions disrupt the surface waters whereas low amplitude millennial scale fluctuations persist in the deep waters as recorded by the oxygen isotope signal. The glacial inception occurred at $\sim 779 \mathrm{ka}$, in agreement with an increased abundance of tetra-unsaturated alkenones, reflecting the influence of icebergs and associated meltwater pulses and high-latitude waters at the study site. After having combined the new results with previous data from the same site, and using a variety of time series analysis techniques, we evaluate the evolution of millennial climate variability in response to changing orbital boundary conditions during the Early-Middle Pleistocene. Suborbital variability in both surface- and deep-water records is mainly concentrated at a period of $\sim 11 \mathrm{kyr}$ and, additionally, at $\sim 5.8$ and $\sim 3.9 \mathrm{kyr}$ in the deep ocean; these periods are equal to harmonics of precession band oscillations. The fact that the response at the $11 \mathrm{kyr}$ period increased over the same interval during which the amplitude of the response to the precessional cycle increased supports the notion that most of the variance in the $11 \mathrm{kyr}$ band in the sedimentary record is nonlinearly transferred from precession band oscillations. Considering that these periodicities are important features in the equatorial and intertropical insolation, these observations are in line with the view that the low-latitude regions play an important role in the response of the climate system to the astronomical forcing. We conclude that the effect of the orbitally induced insolation is of fundamental importance in regulating the timing and amplitude of millennial scale climate variability.
\end{abstract}

(C) 2014 Elsevier Ltd. All rights reserved.

\footnotetext{
* Corresponding author. Tel.: +39041 2348504; fax: +390412348549.

E-mail addresses: patrizia.ferretti@idpa.cnr.it, patrizia.ferretti@unive.it (P. Ferretti).
}

\section{Introduction}

It has long been recognised that the long-term climatic variations deduced from the geological records are driven by the insolation changes forced by variations in Earth orbital geometry 
(Adhémar, 1842; Croll, 1867a,b; Hays et al., 1976; Berger, 1988). Whether these orbitally induced insolation changes modulated or even triggered climate variability in the millennial band is still open to question. A possible feature, which has hindered the inclusion of the orbital or astronomical input as a plausible forcing for rapid climate variability, has been the difference between the primary Milankovitch periods (i.e. the shortest $19 \mathrm{kyr}$ ) and the timing of abrupt climate changes (a few kyr). However, the climate system may behave as a highly nonlinear system and it is conceivable that forcing with frequencies much lower (e.g. a few kyr) than those of its own free oscillations (e.g. 100, 41, 19-23 kyr) can influence its response.

The potential for suborbital climate variability arising as a nonlinear response to Milankovitch forcing was suggested by modelling studies (e.g., Wigley, 1976; Ghil and Le Treut, 1981; Le Treut and Ghil, 1983; Short et al., 1991; Rial and Yang, 2007) and lately observed in different palaeoclimatic spectra (Hagelberg et al., 1994; Ortiz et al., 1999; Wara et al., 2000). Oscillations at frequencies equal to precession harmonics ( $11 \mathrm{kyr}$ and $5.5 \mathrm{kyr}$ ) have been identified in different surface water records (McIntyre and Molfino, 1996; Niemitz and Billups, 2005; Weirauch et al., 2008; Billups et al., 2011; Hernández-Almeida et al., 2012) and recently we have presented evidence that not only surface- but also deep-water records vary on such timescales during the Early Pleistocene (Marine Isotope Stages (MIS) 23-20, 910-790 ka) in the North Atlantic Ocean (Integrated Ocean Drilling Program - IODP - Expedition 306, Site U1313) (Ferretti et al., 2010). The specific mechanisms by which these orbitally induced insolation changes produced the observed climate responses are still poorly understood; however, a good correlation between our surface and deep-water hydrography reconstructions and the tropical insolation forcing have supported the hypothesis that the timing of abrupt climate changes, as well as the amplitude of millennial scale oscillations, may be strongly influenced by insolation variations at the low latitudes.

In order to investigate the temporal extent of these events, and verify whether the harmonics of precession were a recurring feature of the Pleistocene climatic variability, here we extend our observations at IODP Site U1313 to an interval of time characterised by different orbital configurations and place special emphasis on MIS 19. Similarly to the Holocene, MIS 19 was close to the minimum in the $c .400 \mathrm{kyr}$ eccentricity envelope (i.e. the Earth's orbit was close to circular) thus minimising the effect of precession; this is because eccentricity modulates the climatic precession parameter which controls most of the long-term variations of the daily insolation received from the Sun (Berger et al., 1993). It follows that the major feature of the insolation over this interval is the small amplitude of its variations. We set out with the aim of investigating millennial-scale variability in North Atlantic sea surface and deepwater hydrography during MIS 19 and comparing such variations with those from our earlier study focussing on the older portion of the record (MIS 23-20). Our final objective is the assessment of the nonlinear coupling to climatic forcing recorded in the geological record via changes in orbital precession. More specifically, our working hypothesis is that if the insolation determines, in the end, the timing and amplitude of rapid climate change, during MIS 19 we would expect a weaker spectral power at periodicities associated with the harmonics of the precession band, together with relatively low amplitude oscillations aligned with intervals of low precessional forcing (i.e. periods of low eccentricity). We will see that this appears to be the case.

\section{Regional setting}

The sediments used for this study were recovered from Site U1313, a reoccupation of Deep Sea Drilling Project (DSDP) Leg 94
Site 607, during Expedition 306 of the Integrated Ocean Drilling Program (Expedition 306 Scientists, 2006; Stein et al., 2006). This site is located in the North Atlantic on the upper middle western flank of the Mid-Atlantic Ridge, $400 \mathrm{~km}$ WNW of the Azores $\left(41^{\circ} 00^{\prime} \mathrm{N}, 32^{\circ} 58^{\prime} \mathrm{W}\right)$ (Fig. 1). At present, Site $\mathrm{U} 1313$ is predominantly influenced by the surface waters of the North Atlantic Current (Fratantoni, 2001) and, at a water depth of $3426 \mathrm{~m}$, is under the influence of North Atlantic Deep Water (NADW). During glacial periods however, the site became regularly influenced by highlatitude waters as evidenced by low alkenone-based sea-surface temperatures and appearance of ice-rafted debris (Naafs et al., 2011, 2013). In addition, the more negative carbon isotope values observed during glacials over the Pleistocene indicates that this location is sensitive to past changes in the relative contribution of high $\delta^{13} \mathrm{C}$ NADW and low $\delta^{13} \mathrm{C}$ southern source waters and to changes in the locations of these two water masses (Raymo et al., 1990, 2004; Ferretti et al., 2010; Voelker et al., 2010).

\section{Materials and methods}

\subsection{Stable isotopes}

The composite section of Site U1313 was sampled at a constant $1-\mathrm{cm}$ spacing following the shipboard secondary splice between 35.94 and $38.39 \mathrm{~m}$ composite depth (mcd), corresponding to the interval MIS 19. The spliced stratigraphic section was refined postcruise using shipboard magnetostratigraphy, lightness and magnetic susceptibility measurements to provide more accurate correlation points, and the sampled depth-series corresponds to 36.30 and 38.40 revised metres composite depth (rmcd) (=amended metres composite depth - amcd - in Naafs et al. (2012)).

Sediment samples were processed following standard procedures that involve disaggregating the samples in reverse osmosis (RO) water overnight on an orbital shaker and washing them through a $63 \mu \mathrm{m}$ sieve to isolate the sand size fraction. Changes in surface and deep-water hydrography were inferred from variations in stable isotopes on planktonic and benthic foraminifera, respectively. About 20 specimens of the planktonic foraminifera Globigerina bulloides were used for each mass spectrometric analysis to provide ample carbon dioxide; specimens were selected from the 315-355 $\mu \mathrm{m}$ size fraction to minimise noise arising from isotopic changes during ontogeny. Between 5 and 10 specimens of Cibicidoides wuellerstorfi were picked, mostly from the fraction $>212 \mu \mathrm{m}$. After picking, specimens were lightly crushed and cleaned ultrasonically with methanol for a few seconds to remove fine-grained particles; excess liquid and residues were then removed with a pipette, and samples were dried under a vacuum hood. All isotope measurements were made using a ThermoFinnigan-MAT 252 isotope ratio mass spectrometer coupled with a Kiel II carbonate preparation device at the Serveis Científico-Tècnics of the University of Barcelona and are reported referenced to the Vienna Pee Dee Belemnite (VPDB) standard using NBS-19 for calibration. Analytical precision was better than 0.08 for $\delta^{18} \mathrm{O}$ and 0.04 for $\delta^{13} \mathrm{C}$. C. wuellerstorfi $\delta^{18} \mathrm{O}$ values were adjusted for species-specific offsets relative to Uvigerina spp. (widely considered to precipitate its calcite in oxygen isotopic equilibrium with respect to seawater) by adding $+0.64 \%$ VPDB (Shackleton and Opdyke, 1973).

Several duplicate measurements at the same depth were performed on G. bulloides between 37.15 rmcd and 38.29 rmcd; this procedure was adopted not because the results of the initial measurements were suspected to be aberrant but rather to confirm the observed pattern of higher amplitude oscillations in the planktonic $\delta^{18} \mathrm{O}$ signal. The replicate analyses did not deviate from the original measurements and the results were then averaged. 


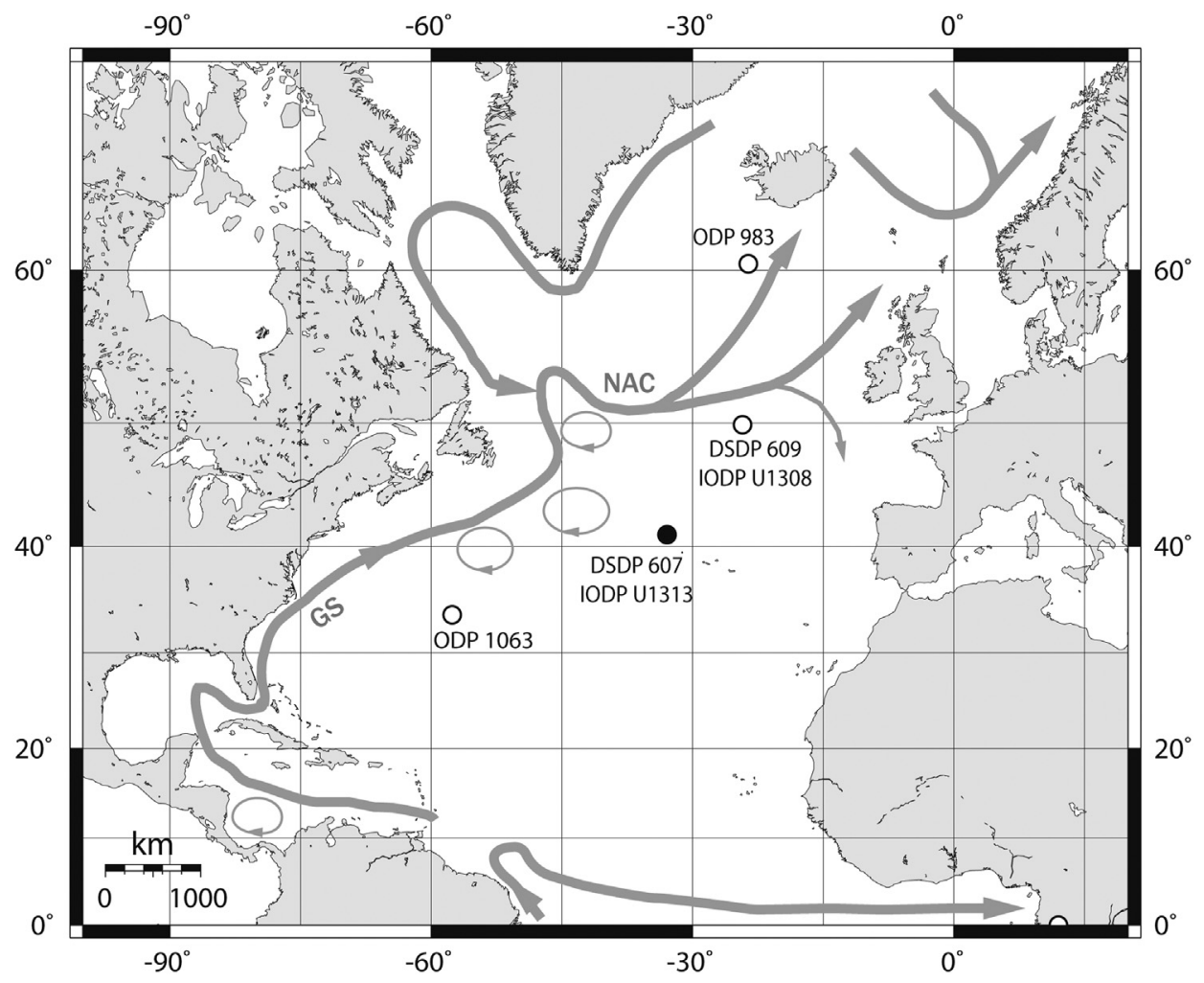

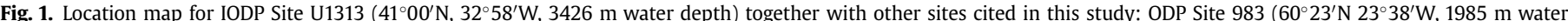

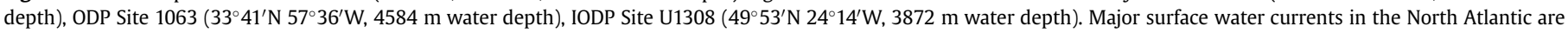
from Fratantoni (2001). GS = Gulf Stream; NAC $=$ North Atlantic Current.

\subsection{Age model}

We tried several strategies for developing a geological time scale based on the cyclicity observed at Site U1313, and the best approach was to develop an age model within the Lisiecki and Raymo (2005) stack framework and subsequently confirm the resulting depth-totime conversion by fine-tuning of the extracted precession component of the climate signal to the precession parameter. In detail, an initial chronology was derived by correlating the Site $\mathrm{U} 1313$ benthic $\delta^{18} \mathrm{O}$ signal to the stacked $\delta^{18} \mathrm{O}$ record of Lisiecki and Raymo (2005) (from now onwards LR04) because this proved an effective and well-documented target for the lower part of the sequence (Ferretti et al., 2010). Above $37.70 \mathrm{rmcd}$ (c. $766 \mathrm{ka}$ on this preliminary time scale) however, it was not a straightforward process to bring the climate variability observed at Site U1313 into phase with the LR04 tuning target, mainly because the benthic $\delta^{18} \mathrm{O}$ signal shows little variability in the most recent part of the record and this pattern-matching exercise become ambiguous (Fig. 2a) the relatively stable conditions recorded at Site U1313 diverge from other deep-water reconstructions from the North Atlantic, where three distinct oscillations in $\delta^{18} \mathrm{O}$ benthic values were recorded during the MIS19c-19b transition (Ferretti et al., 2005; Kleiven et al., 2011) (Fig. S1). On the other hand, this is an interval over which the planktonic record from Site U1313 departs markedly from the benthic one by showing higher amplitude oscillations (Fig. 2b). We then used orbital parameters to fine-tune our records based on the LR04 chronology. The first step we performed was to join the new results from MIS 19 with the previously published foraminiferal stable isotope records from this site (Ferretti et al. 2010), in order to obtain a sequence long enough for statistical analyses. The second step was to identify in this sequence the imprint of a particular component of the orbital forcing and in particular to assess the presence of the higher frequency orbital parameter, the precession component. Spectral analysis of the entire length of these records on the initial LR04 chronology shows that there is a concentration of power at the precession band in all the isotope records reconstructed from Site U1313, and this component is strongest in the planktonic $\delta^{18} \mathrm{O}$. The third step was to refine our age model by matching a $20 \mathrm{kyr}$ filter of the planktonic $\delta^{18} \mathrm{O}$ to the precession index, while maintaining the LR04 stack (which exhibits significant coherency with insolation in both the obliquity and precession bands) as the main tuning framework. At the outset, the planktonic $\delta^{18} \mathrm{O}$ dataset was filtered in the precessional frequency range in the time domain because this procedure assists in aligning core segments containing a precessional signal alongside the other primary Milankovitch frequencies. We proceeded on the assumption that the $\delta^{18} \mathrm{O}$ record has responded to forcing with the same time-constant throughout the interval under discussion, a premise that has been adopted for generating different timescales in the last decades (among others, Shackleton et al. (1990)). In order to quantify the time-constant, we have determined the phase relationship between precession and the planktonic $\delta^{18} \mathrm{O}$ record from core MD 95-2042 on the Iberian margin off southern Portugal (Shackleton et al., 2000). Crossspectral analysis of planktonic $\delta^{18} \mathrm{O}$ from core MD 95-2042 and precession shows that the planktonic $\delta^{18} \mathrm{O}$ lags the precession parameter by $3.3 \mathrm{kyr}$, and the same value was used to define the phase of Site U1313 planktonic $\delta^{18} \mathrm{O}$ relatively to precession. The pattern-matching exercise at Site $\mathrm{U} 1313$ is a relative straightforward process even at above $37.70 \mathrm{rmcd}$ (c. $778 \mathrm{ka}$ on this time scale), the depth at which the benthic $\delta^{18} \mathrm{O}$ signal becomes quite smooth, permitting an unambiguous match with the target to be achieved (Fig. 3). In this manner, the refinement of our record by means of orbital tuning has arguably provided a more accurate time 


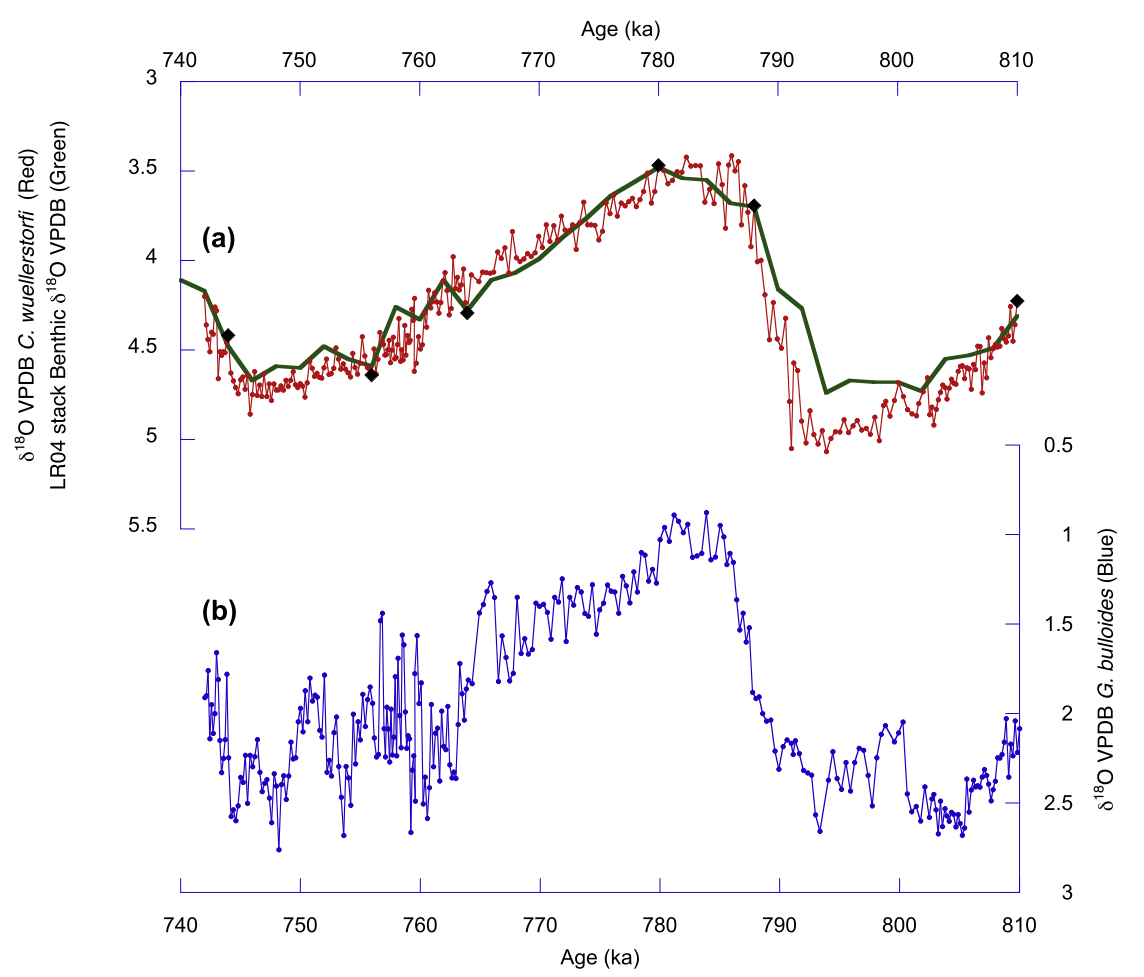

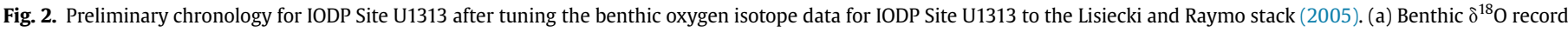

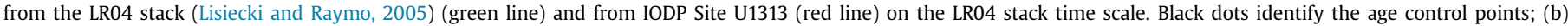

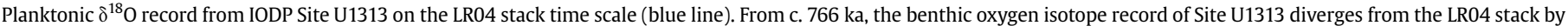

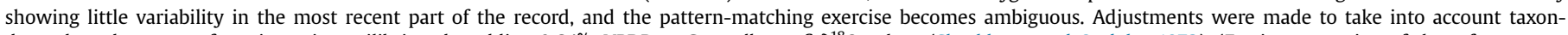

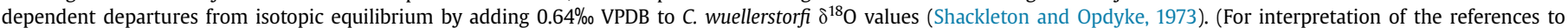
colour in this figure legend, the reader is referred to the web version of this article.)

scale than could have been achieved by solely correlating the benthic $\delta^{18} \mathrm{O}$ to the LR04 stack. For the lower part of the section, from 832 ka (MIS 21-23), we rely on the initial chronology developed by Ferretti et al. (2010) matching the sequence to LR04 stack, since there is no basis for major modification of the proposed age model (Fig. 3). Fig. 4 shows the planktonic and benthic data on a timescale derived by matching to the LR04 record in a manner consistent with the filtering experiment (see also Figs S2 and S3). Table 1 lists the control points that we have used to construct the time-series in Fig. 4, and Fig. 3c illustrates the sedimentation rate picture that emerges from the refined time scales developed in this study. We conclude that our record spans the time interval from $c$. 740 to $910 \mathrm{ka}$. The mean sedimentation rate for MIS 19 is c. $4.5 \mathrm{~cm} /$ $\mathrm{kyr}$, and the sampling interval of $1-\mathrm{cm}$ results in an average temporal resolution of 250 years.

Time-series analysis was performed to test for statistically significant cycles, coherence, and relative phase of proxy signals. Spectral and cross-spectral analysis was conducted with the ARAND software package (http://www.ncdc.noaa.gov/paleo/ softlib/) (Howell et al., 2006), which uses the standard methods of Jenkins and Watts (1968). Confirmatory analyses and bandpass filtering were carried out using Analyseries (Paillard et al., 1996), and REDFIT (Schulz and Mudelsee, 2002) was used to help examine the statistical significance of particular peaks. In addition, wavelet analysis was conducted to assess temporal changes in the periodicity and amplitude of the oxygen isotope variability using the software SOWAS provided by Douglas Maraun (Maraun and Kurths, 2004; Maraun et al., 2007). Confirmatory wavelet analyses were performed using the interactive program provided by $\mathrm{C}$. Torrence and G. Compo and available at URL: http://paos.colorado.edu/ research/wavelets/.

\section{Results}

The oxygen and carbon isotope data from MIS 19-23 are plotted against estimated age in Fig. 4. In order to isolate the low frequency components of our proxy records, we have smoothed the data with a Gaussian interpolation with a $15 \mathrm{kyr}$ window width, which has the effect of providing some smoothing as well as interpolation (Fig. 5). Taking the difference between the full data and the Gaussian interpolation removes the variability shared by the two records - that is the longer periodicity components leaving a residual that reflects the millennial-scale variability in the isotope signal. The result of subtracting the Gaussian interpolation from the observed record is shown in Fig. 5. Time series analyses were performed on the residuals with the object of establishing the dominant periodicities impressed on these records and to show how their amplitude varied over time. Spectral analysis and wavelet analysis are illustrated in Fig. 6, Fig. S5 and Fig. 7 respectively, whereas Fig. S4 presents the results of the REDFIT test aimed to assess the statistical significance of the spectral peaks.

Three features stands out from the overall procedure, which includes the calculation of the Gaussian interpolation, the residuals, cross-spectral analysis and wavelet analysis. First, it is visually clear that the amplitude of the high frequency signal in the planktonic and benthic foraminiferal residuals is far smaller during MIS 19c (Fig. 5). On the other hand, the amplitude of the planktonic $\delta^{18} \mathrm{O}$ residual is quite low during most of MIS 19 but higher amplitude oscillations are present during the MIS 19-18 transition, from c. $778 \mathrm{ka}$. To some extent, this feature is shared by the benthic carbon signal, although its range of variability is lower than during the previous interglacial MIS 21. Second, time 


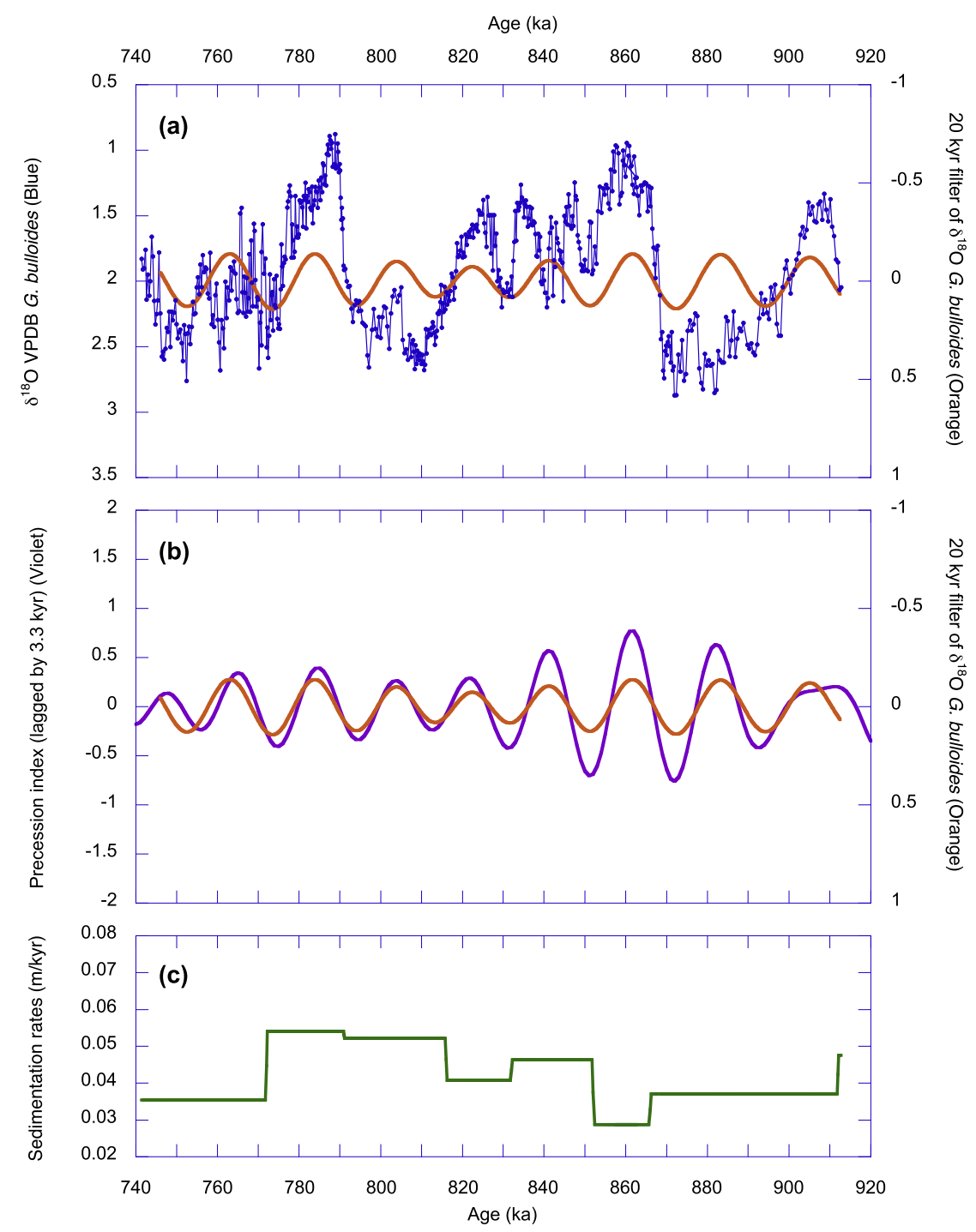

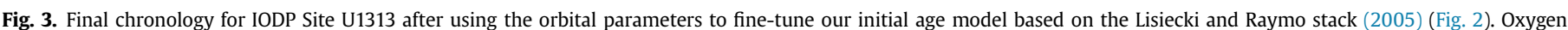

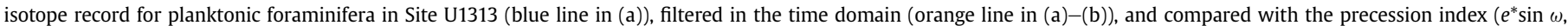

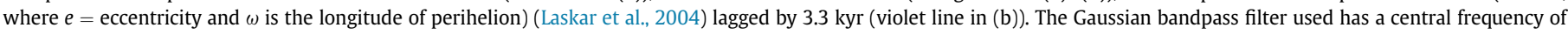

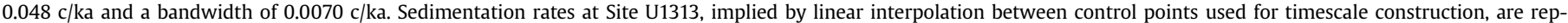
resented in (c). (For interpretation of the references to colour in this figure legend, the reader is referred to the web version of this article.)

series analysis reveals a significant concentration of power at a period of about $11 \mathrm{kyr}$ in the planktonic $\delta^{18} \mathrm{O}$, benthic $\delta^{18} \mathrm{O}$ and benthic $\delta^{13} \mathrm{C}$ residuals (Fig. 6). Cross-spectra of planktonic $\delta^{18} \mathrm{O}$ vs. benthic $\delta{ }^{18} \mathrm{O}$ records indicate high coherency above the $95 \%$ confidence level in the $11 \mathrm{kyr}$ band; the phase offset between the two parameters is about $-35^{\circ}$, which at this periodicity indicates that benthic $\delta^{18} \mathrm{O}$ leads planktonic $\delta^{18} \mathrm{O}$ by about 1080 years (Fig. 6a). Again, there is high coherency between the benthic $\delta^{18} \mathrm{O}$ and benthic $\delta^{13} \mathrm{C}$ in the $11 \mathrm{kyr}$ band, with a lag of benthic $\delta^{13} \mathrm{C}$ against benthic $\delta^{18} \mathrm{O}$ of about $43^{\circ}$, which at this band corresponds to c.1.3 kyr (Fig. 6b). Moreover, well-marked spectral peaks can be observed in the benthic $\delta^{18} \mathrm{O}$ residual at the $\sim 5.8$, 3.9 and $1.7 \mathrm{kyr}$ periodicities and at the period of $\sim 3.7 \mathrm{kyr}$ in the benthic $\delta^{13} \mathrm{C}$ residual (Fig. 6 and Fig. S4). Third, the wavelet analysis seems to indicate changes in activity in the millennial band over the interval of time analysed in this study, with power being less concentrated at $\sim 11 \mathrm{kyr}$ in the most recent part of the time series (after around $820 \mathrm{ka}$ ) (Fig. 7).

\section{Discussion}

\subsection{Validation and discussion on the proposed chronology}

\subsubsection{Comparison of the climate cycles in the depth and time} domains

A quantitative understanding of millennial-scale climate variability beyond the last climate cycle has been hindered by the critical role of age control in interpreting millennial-scale changes and the difficulty of confidently placing the marine records on an accurate time scale beyond the range of radiocarbon dating and the Greenland ice core record. At Site U1313, we have attempted to present the MIS 19 data on a time scale constrained using a specific approach reflecting the distinctive precession signal at this site. Once the whole sequence had been put on a preliminary age model based on the LR04 stack, and it had become clear that it displayed a $20 \mathrm{kyr}$ cyclicity on this time scale, it was possible to refine the age model using the precessional component of the orbital forcing 


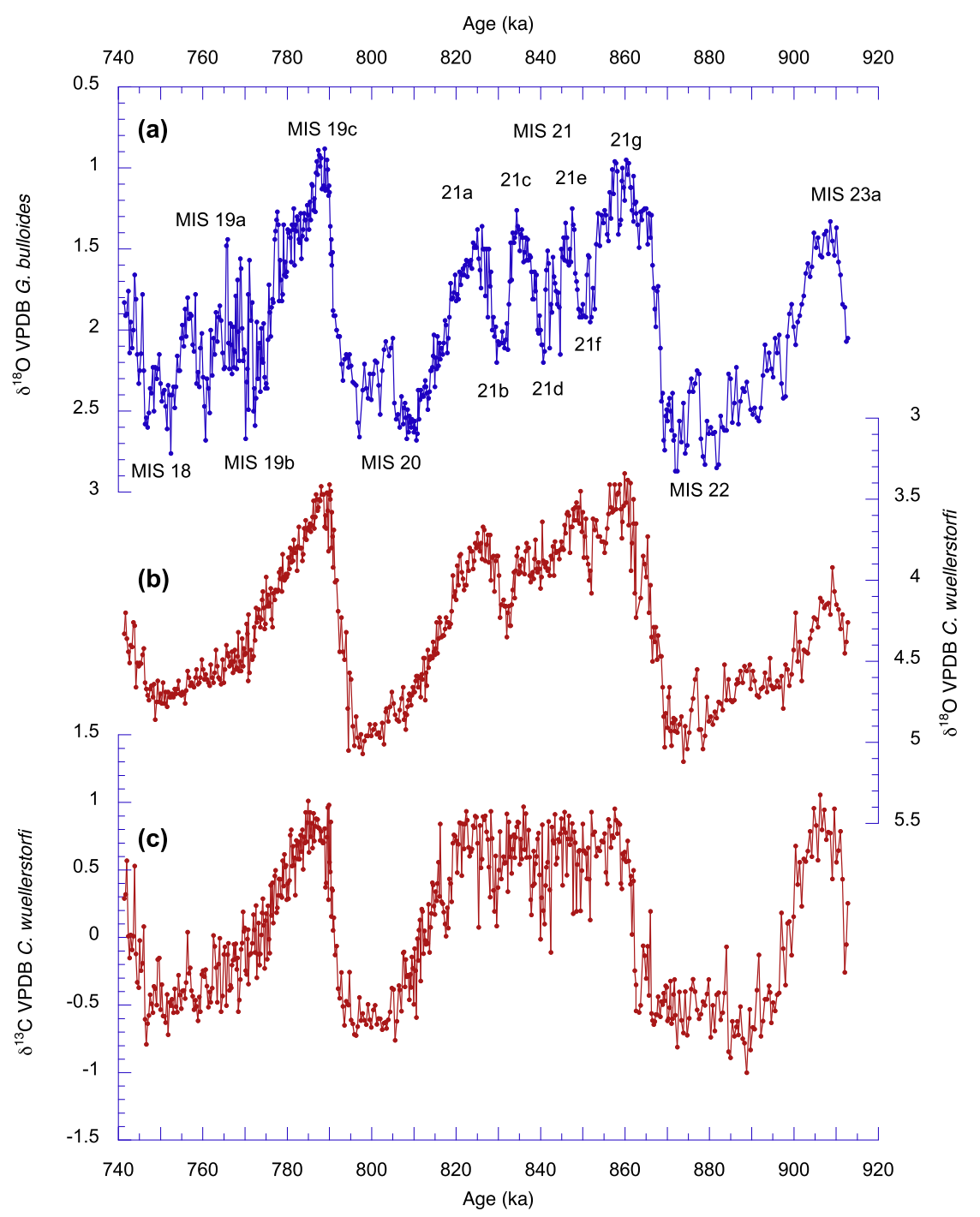

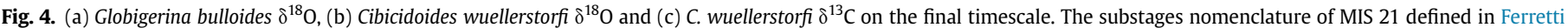
et al. (2010) has been reorganised by using lettered substages (analogous to 5a to 5e in the late Pleistocene) instead of decimal isotopic events.

curve, while maintaining the LR04 stack as the main tuning basis. It must be emphasised that this procedure that matches the sedimentary cycles with a sequence of precession cycles does have the effect of enhancing the coherence with precession. However, it should also be emphasised that this procedure neither introduces the imprint of the precession signal in the sedimentary sequence

Table 1

Age model for Site U1313. The age control points used to construct the time series in Fig. 4. Ages of samples between these control points were estimated by linear interpolation.

\begin{tabular}{|c|c|c|}
\hline \multirow[t]{2}{*}{ Age (ka) } & Depth (rmcd) & Depth (mcd) \\
\hline & Naafs et al. (2012) & Expedition 306 Scientists (2006) \\
\hline 746 & 36.47 & 36.09 \\
\hline 772 & 37.39 & 37.44 \\
\hline 791 & 38.42 & 38.41 \\
\hline 816 & 39.72 & 39.64 \\
\hline 832 & 40.37 & 40.24 \\
\hline 852 & 41.30 & 41.06 \\
\hline 866 & 41.70 & 41.36 \\
\hline 912 & 43.41 & 43.28 \\
\hline
\end{tabular}

nor has any effect on the amplitude of the Milankovitch-scale climate cycles observed at Site U1313. Indeed, after removing the longer periods dominating the records in the depth domain, spectral analysis of the $\delta^{18} \mathrm{O}$ data in the depth domain reveals significant concentrations of spectral power at around $0.84 \mathrm{~m}$ and $0.52 \mathrm{~m}$ in the benthic and planktonic oxygen isotope records (Fig. 8). When converted to time by means of an average sedimentation rate at Site $\mathrm{U} 1313$ of $\sim 4.3 \mathrm{~cm} / \mathrm{kyr}$, these well-marked spectral peaks correspond to periodicities of $\sim 19.5 \mathrm{kyr}$ and $\sim 12$ kyr respectively, and are consistent with a derivation from precession band variations. It might be objected that the $12 \mathrm{kyr}$ periodicity is too long to be a consistent harmonic of the $19.5 \mathrm{kyr}$ period. However, it must be also pointed out that, in order to make this calculation, we proceed with the simplest assumption that the sedimentation rates were constant throughout the interval considered in this study. This is obviously implausible from the geological point of view, and Fig. 3c confirms that that the sedimentation rate picture inferred at Site U1313 is much more complex than being simply constant. Considering how vulnerable the climate cycles are to the distorting non-sinusoidal effects of both the climate system and the geological archive (e.g. high frequency changes in accumulation rate), the similarity between the expected 


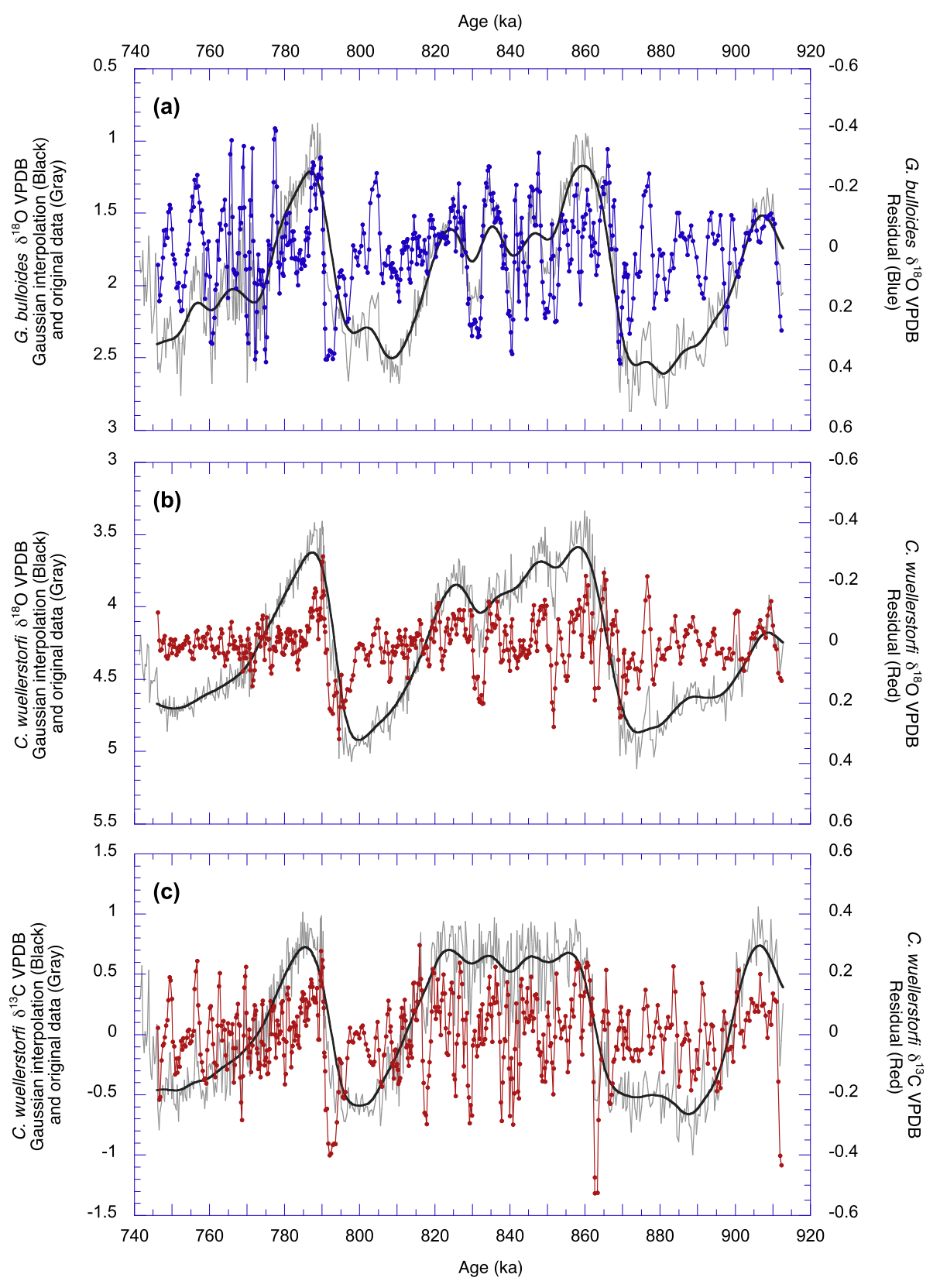

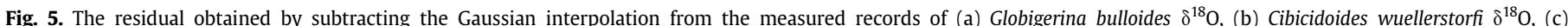

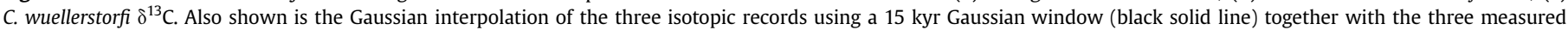

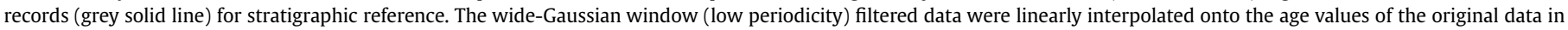
order to conserve the original variance of the data, and the difference obtained.

harmonic (11 kyr, Fig. 6) and the observed harmonic (12 kyr, Fig. 8) is striking. This observation confirms that precession was significant and detectable in the sedimentary sequence before the age model was developed and subsequently refined through the precession signal, and we conclude that the interpretation of these periodicities is not dependent on the choice of our particular age model. As we will discuss extensively in Section 5.2, the modulation of the 10-kyr filtered planktonic data and the eccentricity modulation of the precession component in the model output are remarkably similar and there seems little possibility that this match could have been obtained with an incorrect time scale (Fig. 10a-c). It would of course (as with almost any varying time series) have been possible to introduce a distorted precession-like signal by introducing uncontrolled and spurious accumulation rate variations. The numerous chronological constraints surrounding any actual geological time series from this geological interval, including accumulation rate constraints, make it much more difficult to generate large-scale errors on these timescales than is sometimes supposed (e.g. Proistosescu et al., 2012).

\subsubsection{The glacial inception during Marine Isotope sub-Stage $19 c$}

Another line of evidence supporting our age model interpretation is related to the duration of interglacial conditions during MIS 19. The timing of the glacial inception during MIS 19 has been recently estimated to be $c .777 .5 \mathrm{ka}$ at Ocean Drilling Program (ODP) Site 983 on the Gardar Drift in the North Atlantic (Fig. 1) and constrained by the onset of the bipolar seesaw climate variability, which requires ice-sheets large enough to produce iceberg 


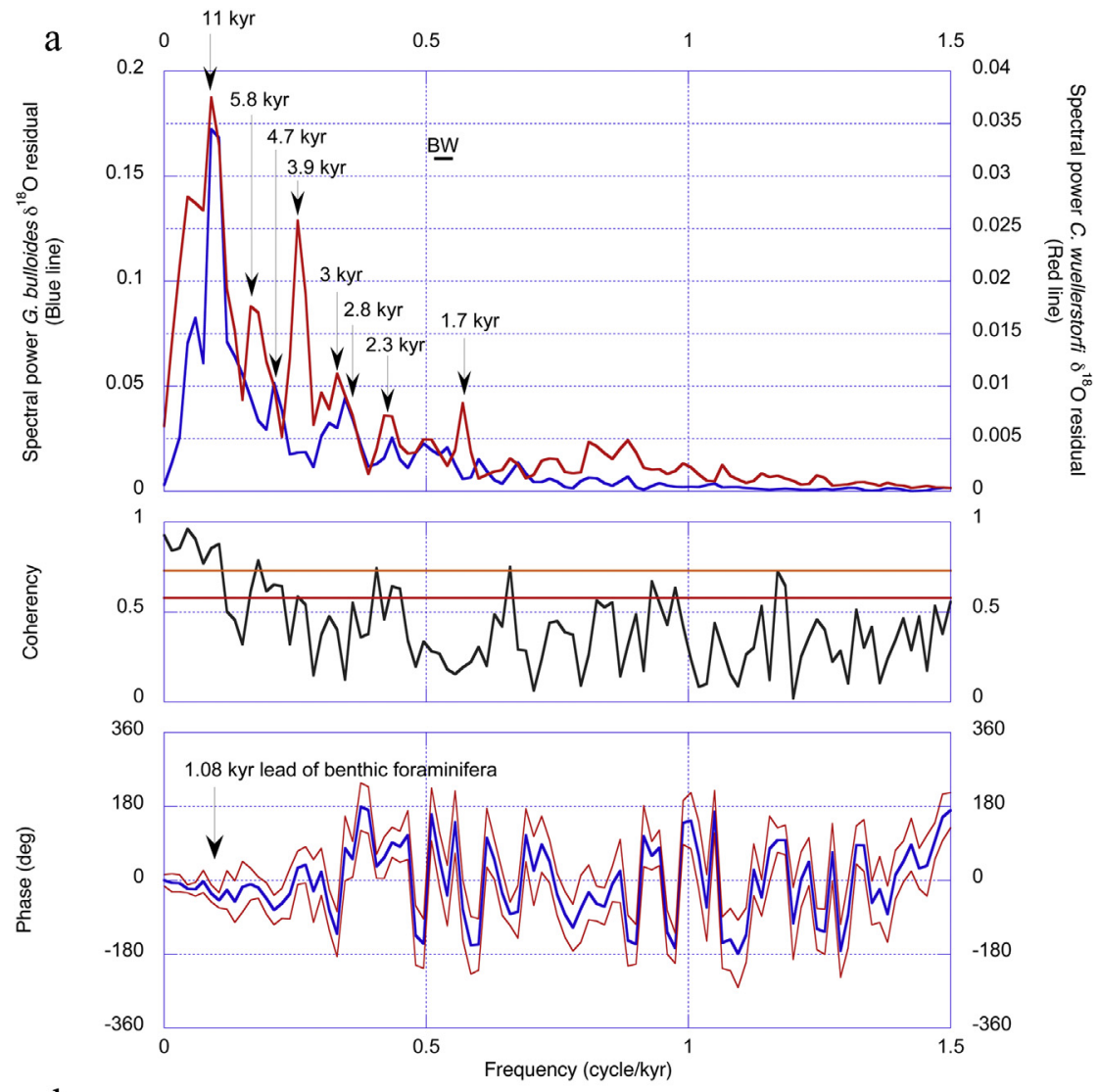

b
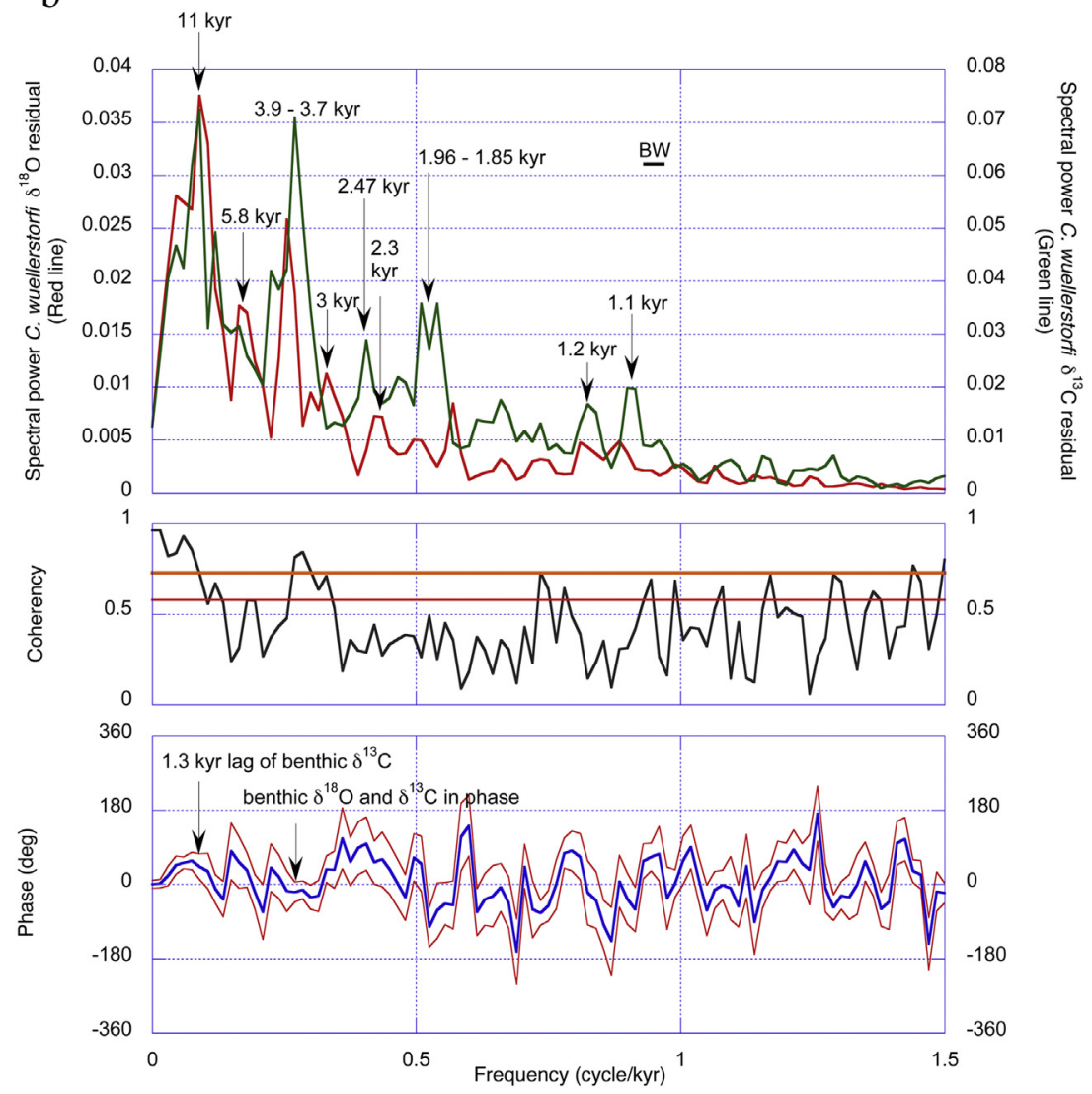

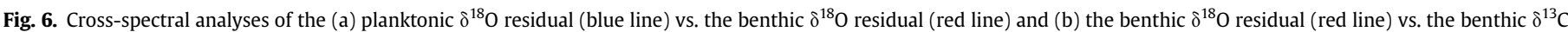

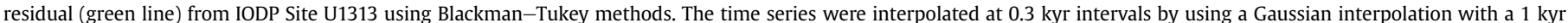

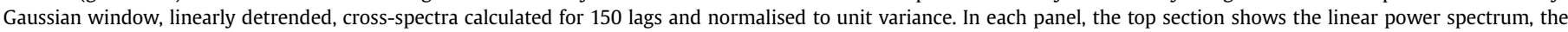


discharges (Tzedakis et al., 2012). The onset of these climatic changes on the Gardar Drift converges with an increased abundance of tetra-unsaturated alkenones $\left(\mathrm{C}_{37: 4}\right)$ at $c .779 \mathrm{ka}$ at IODP Site U1313 (Fig. 9a), reflecting the influence of icebergs and associated meltwater pulses together with high-latitude waters at the study site (Naafs et al., 2011, 2013). Sea-surface temperature (SST) declines, as inferred by both the alkenones-based SSTs (Fig. 9b) (Naafs et al., 2011) and the planktonic $\delta^{18} \mathrm{O}$, are coeval with the arrival of polar melt water to our core location reflecting iceberg discharges from circum-Atlantic ice sheets (Naafs et al., 2011, 2013) and suggest that ice-sheets at that time reached sufficient size to extend to North Atlantic coasts and calve along coastlines despite the weak eccentricity-precession parameters and the subdued insolation forcing. Our estimate for the timing of the glacial inception during MIS 19, constrained by an increase in the relative proportion of tetraunsaturated $C_{37}$ alkenone, is within the uncertainties of the Gardar Drift age model, regardless of the two different dating approaches, and provides a validation of our tuned timescale.

Increases in this compound also occurred from c. $776 \mathrm{ka}$ onwards, suggesting multiple events of enhanced iceberg discharges into the North Atlantic as a result of instability of Northern Hemisphere ice sheets; the meltwater originating from these icebergs decreased both sea surface temperature and salinity, and this is consistent with the observed increased amplitude oscillations in the planktonic $\delta^{18} \mathrm{O}$ signal that disrupted the transition toward glacial MIS 18. Salinity perturbations, resulting from iceberg discharges could have also reduced the meridional overturning circulation in the Atlantic Ocean and affected millennial-scale fluctuations in deep water circulation as recorded by pronounced millennial scale-variations in the benthic foraminiferal $\delta^{13} \mathrm{C}$ record (Fig. 9c).

\subsection{Harmonics of precession-induced oscillations}

The important conclusion that can be drawn from the examination of our isotope records is that palaeoclimate spectra from Site U1313 clearly reveal a significant concentration of power at a period of about $11 \mathrm{kyr}$; a well marked concentration of variance is also present in the $5.8 \mathrm{kyr}$ band in the benthic $\delta^{18} \mathrm{O}$ record, and these periodicities are very close to periods related to the second and fourth harmonics predicted from the primary precessional components (Berger et al., 2006). While the Milankovitch theory - that the timing of variations in global climate is paced by variations in Earth's orbital parameters - has been incorporated in mainstream literature, much less is known about high frequency variability resulting from a transfer of variance from primary orbital frequencies.

The potential for a nonlinear climate response to Milankovitch forcing in the millennial band has been predicted in modelling studies since the late 1970s (e.g., Wigley, 1976; Ghil and Le Treut, 1981; Le Treut and Ghil, 1983; Short et al., 1991; Berger et al., 2006). More recently, Rial and Yang (2007) illustrated an example of such a mechanism by showing that there is an important effect of insolation on the Dansgaard-Oeschger pulses of the last $100 \mathrm{ka}$ recorded in the Greenland Ice Core Project (GRIP) ice core, which these authors consider affects the timing of the abrupt climate change episodes through a process related to frequency modulation. In more detail, the high-pass filtered GRIP time series has been shown to have a power spectrum with a main peak at $4.46 \mathrm{kyr}$ and four flanking peaks at 2.97, 3.6, 6.2, and $9.3 \mathrm{kyr}$, which are consistent with the predicted line spectrum of a sinusoid of period $4.46 \mathrm{kyr}$ frequency modulated by a $19 \mathrm{kyr}$ oscillation. In order to make these observations more concrete, these authors also demonstrated that the GRIP time series could be closely reproduced by a simple, non-linear differential equation representing the climate response forced by the Milankovitch-cycle determined insolation. Although their conclusion, that the timing of abrupt climate changes may be strongly influenced by insolation through frequency modulation, was based upon analyses of the stable isotopes in the GRIP time series covering the last $100 \mathrm{ka}$, it is reasonable to expect that the physical mechanisms involved and nature of the nonlinearities may have been much the same when the orbital boundary conditions were different from the last ice age, as for example in the Early-Middle Pleistocene.

The existence of a nonlinear climate system response to the Milankovitch band processes has additionally been identified in other palaeoclimate data analyses, and suborbital scale oscillations containing periodicities close to the second and fourth harmonics of precession (c. 11 and $5.5 \mathrm{kyr}$ respectively) have been observed in surface records from different locations (McIntyre and Molfino, 1996; Niemitz and Billups, 2005; Weirauch et al., 2008; Billups et al., 2011; Hernández-Almeida et al., 2012; Billups and Scheinwald, 2014). More recently, it has been shown that not only surface but also deep-water reconstructions from the North Atlantic contain the same periodicities during the Middle Pleistocene (Ferretti et al., 2010; Billups et al., 2011), suggesting that this nonlinear coupling to climatic forcing via changes in orbital precession also affects the deep limb of the meridional overturning cell.

In this paper we show an additional reason to believe that changes in the Earth's orbital geometry and their effect on the seasonal distribution of insolation are a plausible driver for climate variability on millennial timescales at Site U1313. Wavelet analyses of the $\delta^{18} \mathrm{O}$ residuals, which yield information on both the amplitude of periodic signals within the series and how this amplitude varies with time, show significant concentration of variance close to half precession during the portion of the record when precession forcing is also strong (880-830 ka) (Fig. 7). Between 880 and $850 \mathrm{ka}$, when precession exhibits the largest amplitude variations of the time interval considered in this study, spectral power in the benthic $\delta^{18} \mathrm{O}$ record also contains periodicities related to the fifth harmonic of precession (c. $3.9 \mathrm{kyr}$ ). On the other hand, in the planktonic $\delta^{18} \mathrm{O}$ record, lower - although still significant - power in the $11 \mathrm{kyr}$ band is displayed between 800 and $750 \mathrm{ka}$, which corresponds to an interval of subdued precessional variations as a result of low eccentricity values. Considering that the effect of precession on the seasonal distribution of solar radiation is also modulated by orbital eccentricity, the major feature of the insolation over this time intervals is the small amplitude of its variations. Thus, our results suggest a dependence of climate variability on millennial timescales at Site U1313 to orbitally induced insolation changes in such a way that insolation seems to drive or pace climate change directly and proportionally during the interval of time considered in this study.

In order to make these statements more concrete, we have reviewed the specific mechanisms by which insolation changes produce the observed climate responses. A possible scenario

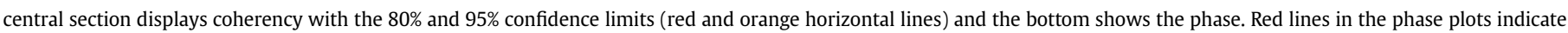

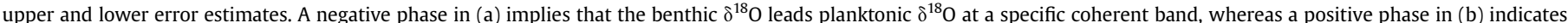

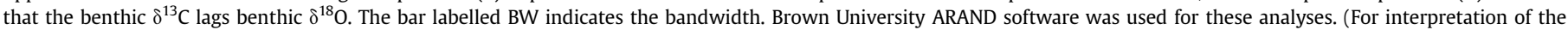
references to colour in this figure legend, the reader is referred to the web version of this article.) 

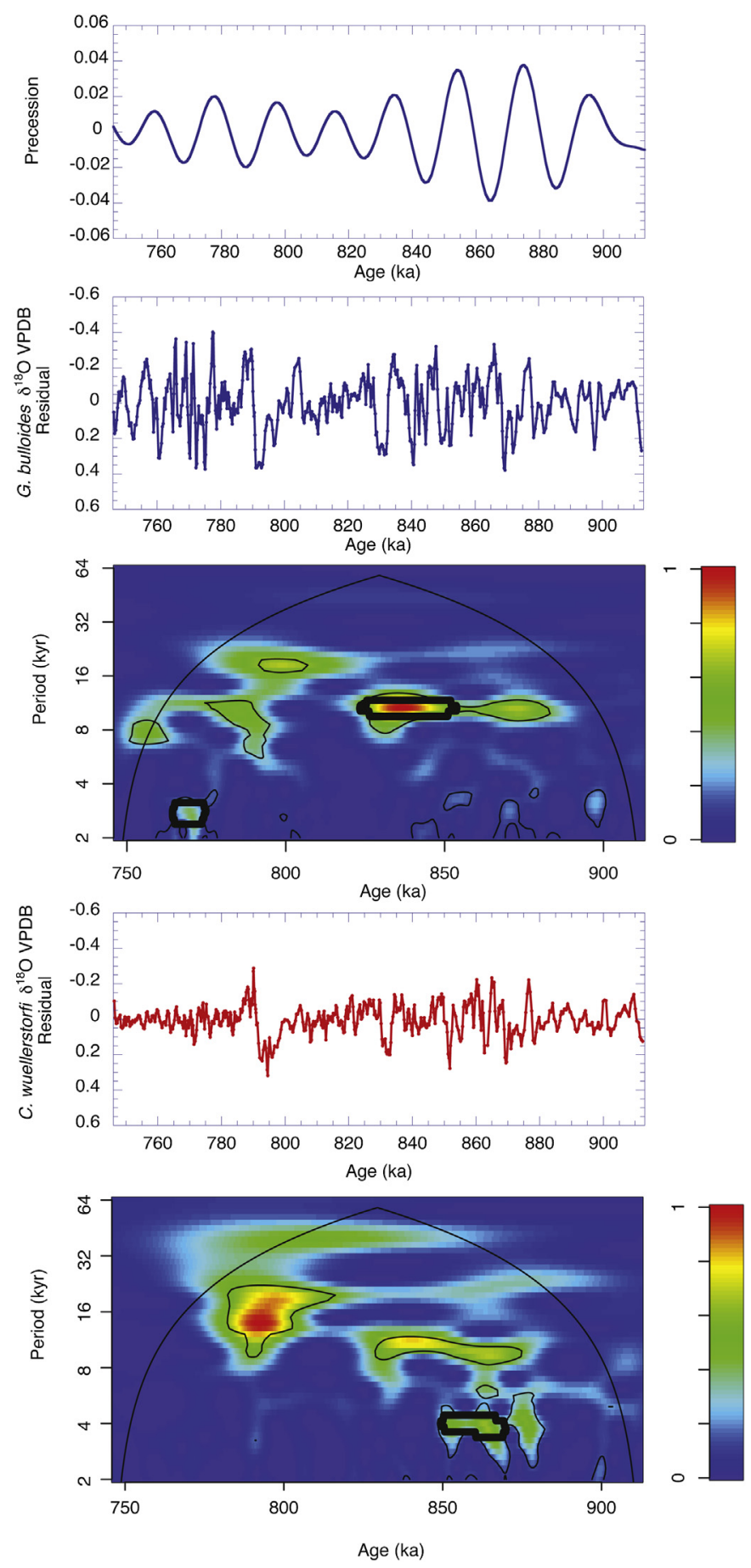

Fig. 7. Wavelet analysis of the G. bulloides $\delta^{18} \mathrm{O}$ residual and C. wuellerstorfi $\delta^{18} \mathrm{O}$ residual. For wavelet analysis, the residuals were interpolated at a constant 1 kyr time interval. For reference, the time series together with the precession parameter (Laskar et al., 2004) is shown. Note that spectral power at the suborbital periods in the proxy record is stronger between 880 and 830 ka when the precession forcing has relatively large amplitude. At around $780 \mathrm{ka}$, the 'overshoots' associated with the deglaciation generate spectral components at around $20 \mathrm{kyr}$ and $10 \mathrm{kyr}$, but not the higher frequency components associated with precession maxima. Note that some variance associated with obliquity is still present in the dataset after high-pass filtering.

involves the generation of half precessional climate variability in the Equatorial and intertropical regions, which is then advected to the high latitudes by either atmospheric or oceanic circulation with little lag. In this scenario, a complex response of maximum surface temperature to insolation forcing in equatorial regions is generated when the perihelion of the Earth's orbit coincides with the vernal or autumnal equinox; because this combination occurs twice in every precession cycle, it creates a precession cycle harmonic at 10-12 cycle/kyr (Short et al., 1991). A direct consequence of this process would be an amplified response of tropical precipitation and temperature to changes in maximum summer insolation, a response that may then be transferred from equatorial latitudes to the higher latitudes of the North Atlantic via advective transport (Short et al., 1991; Hagelberg et al., 1994). Another scenario that has been proposed to explain semiprecession cycles, that are phase coupled to both precession and eccentricity, invokes the export of a Southern Hemisphere precessional signal to the Northern Hemisphere; because the hemispheres are $180^{\circ}$ out of phase with respect to precession, this process generates semiprecession cycles in the Northern Hemisphere (Rutherford and D'Hondt, 2000). Both the first and the second scenario involve two precessional cycles that are $180^{\circ}$ out of phase, but in the first hypothesis the cycles are generated by the alignment of perihelion with each equinox, while in the second one they are produced by the alignment of perihelion with each solstice.

We have already demonstrated using cross-correlation coefficients that the first scenario, which invokes a low-latitude equinoctial forcing, provides a more complete and effective explanation for the observed proxy response at IODP Site U1313 during MIS 23-20 than the high-latitude forcing (Ferretti et al., 2010). To evaluate if this is a consistent feature of Middle Pleistocene suborbital climate, we have extended to MIS 19 the comparison between our records and a) the insolation at the Equator in March-April and September-October (Laskar et al., 2004; Fig. 10b), in order to test the hypothesis suggested by Short et al. (1991), and b) the insolation at both $65^{\circ} \mathrm{N}$ in June-July and $65^{\circ} \mathrm{S}$ in December-January (Laskar et al., 2004; Fig. 10d) to assess the mechanism proposed by Rutherford and D'Hondt (2000). Fig. 10 draws attention to the overall similarity between trends in forcing and data and it is visually clear that a very good match exists between the amplitude modulation in the 10-kyr Gaussian bandpass filter of the planktonic and benthic foraminiferal $\delta^{18} \mathrm{O}$ residual (Fig. 10c) and insolation at the Equator during the Equinoxes (Fig. 10b). Our proxy records mimic the equatorial insolation sequence remarkably well, both in terms of timing, phase and amplitude. The attenuated signal in the benthic and planktonic isotope records from c. 820 to $750 \mathrm{ka}$ mirrors the subdued insolation variations and low amplitude precessional changes (Fig. 10a), which are due to the modulation effect of the 400-kyr eccentricity cycle. The phase offset between the timing of changes in the insolation and the proxy records likely reflects a delay in the response of the climate system to the astronomical forcing and, at least for the most recent part of the record (c. 816-741 ka) is a consequence of the way in which the orbitally tuned age model was reconstructed.

\subsection{MIS 19, an excellent analogue for the Holocene: insights from} cross-correlation coefficients between the forcing and the proxy response

To investigate the match between the hypothesised possible forcings for the $10 \mathrm{kyr}$ cyclicity in U1313 - Equinoxes at the Equator and Solstices at both $65^{\circ} \mathrm{N}$ and $65^{\circ} \mathrm{S}$ - we compared the amplitude modulation of the forcing and the proxy response, that we extracted using the upper amplitude envelope of the variables. We ran a Pearson Product-Moment cross-correlation at 1 kyr steps for the U1313 upper amplitude envelope of the $10 \mathrm{kyr}$-filtered planktonic and benthic $\delta^{18} \mathrm{O}$ response against the upper amplitude envelope of possible $10 \mathrm{kyr}$ forcings for a full $1.5 \mathrm{Ma}$ interval of forcing (Fig. 11). In our calculation of the cross-correlation coefficients, we focussed on the upper amplitude envelopes of the variables only on 


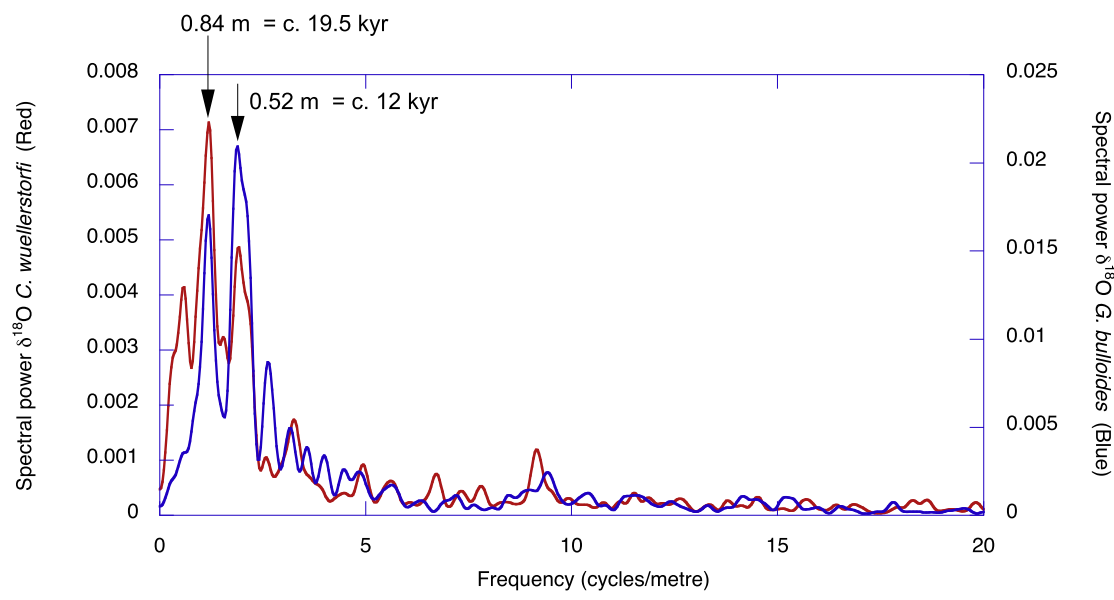

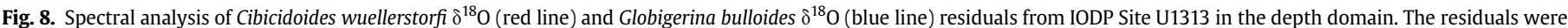

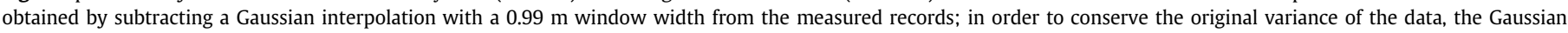

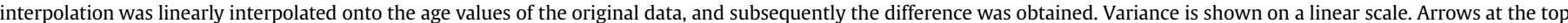

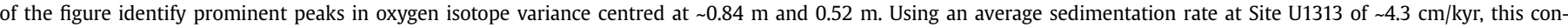

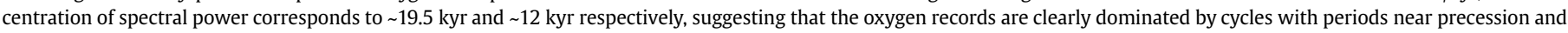
half-precession even before orbital tuning. (For interpretation of the references to colour in this figure legend, the reader is referred to the web version of this article.)

the assumption that warming responses would be driven by the higher insolation. This procedure at first sight might appear pointless: why compare the climatic response to a wide range of orbital forcings, most of which cannot possibly have been responsible for driving the observed time series? However, the exercise addresses three questions: first, whether the observed pattern of amplitude modulation is better explained by equinoctial or solstice forcing, regardless of its precise placement in time by the tuning; second, whether the amplitude modulation match is a coincidence, or is unlikely to have arisen by chance in relation to the overall range of amplitude modulation over the last $1.5 \mathrm{Ma}$; and thirdly, whether the pattern of sub-Milankovitch amplitude modulation observed around the geological interval MIS 19 is relevant to orbitally governed climate behaviour at other intervals of the late Pleistocene, in particular the Holocene and MIS 11, the latter of which is often considered as a potential analogue for the Holocene and its future (Loutre and Berger, 2000, 2003).

The results appear to provide answers to all three questions (Fig. 11). The calculated equinoctial forcing in the vicinity of MIS 19 is more strongly correlated with the observed response than is the calculated solstice forcing (for benthic $\delta^{18} \mathrm{O}, r^{2}$ is a maximum 0.849 at $755 \mathrm{ka}$ for the start of the sequence, versus 0.685 for solstice forcing at $754 \mathrm{ka}$; for planktonic $\delta^{18} \mathrm{O}$, maximum $r^{2}$ for equinoctial forcing is 0.915 at 762 ka start age, versus a maximum 0.675 with $762 \mathrm{ka}$ as the start of the sequence for solstice forcing). The correlation between forcing and response is strong only in a few intervals of the studied time range, and is therefore less likely to have arisen by chance, especially considering that the $10 \mathrm{kyr}$ cycles and their amplitudes were not themselves tuned. In particular, the amplitude modulation of the $10 \mathrm{kyr}$ cycle observed in our data (and that we extracted using the upper amplitude envelope) from $c$. $740-910 \mathrm{ka}$ is consistent with forcing at only three places in the last 1.5 million years: where it is (i.e. with the climate response occurring $750 \mathrm{kyr}$ prior to the present), $380 \mathrm{ka}$ ago, and close to the present. Therefore this comparison highlights the fact that the orbital configuration apparently echoed by the climatic response is most closely comparable to the configurations around MIS 11 and MIS 1, emphasising that the millennial-scale variations around MIS 19 are particularly relevant to the Holocene. In more general terms, the analysis presented here makes a very strong case for concluding that during MIS 19 the orbital forcing at sub-Milankovitch periodicities - and the climate response at this site - is very close to that which we might expect at present and in the future (i.e. next $5 \mathrm{kyr}$ ) if natural rather than anthropogenic forcings govern the climate behaviour.

\subsection{Phasing of harmonics of precession events}

The nature of the phase relationship among co-registered proxies from IODP Site U1313 clearly deserves some attention. Cross-spectral analysis shows that benthic and planktonic isotope variability is concentrated in the half-precession bandwidth, with high coherency, and with the benthic $\delta^{18} \mathrm{O}$ leading both planktonic $\delta^{18} \mathrm{O}$ and benthic $\delta^{13} \mathrm{C}$ by around 1080 and 1300 years, respectively (Fig. 6). At DSDP Site 607, of which Site U1313 represents a reoccupation, sea surface temperature lags behind benthic $\delta^{18} \mathrm{O}$ by around 3000 years in the precessional band, and benthic $\delta^{13} \mathrm{C}$ also shows a substantial lag behind $\delta^{18} \mathrm{O}$ (Ruddiman et al., 1989); at this site, the phase relationship is evaluated on a longer periodicity but, very interestingly, the same sequence seems to apply, even if less quickly. Thus, palaeoclimate variability in the precession band displays the same phasing as variability at periodicities equal to half-precession harmonic, indicating that the same sequence of events characterised the climate oscillations involved, at both primary and harmonic frequencies. One of the difficulties of understanding such phase relationships is represented by the fact that each climate proxy time series is influenced by different components of the climate system and, in turn, each component has potentially a different phase relative to its orbital forcing. In particular, the benthic $\delta^{18} \mathrm{O}$ signal reflects a combination of deepwater temperature effects and a water $\delta^{18} \mathrm{O}$ component; in turn, the water $\delta^{18} \mathrm{O}$ signal echoes both global effects (i.e. ice volume) and local hydrographic effects due to changes in the $T-\delta^{18} \mathrm{O}$ signature of deep-water bathing the core site. The benthic $\delta^{18} \mathrm{O}$ signal has recently been deconvolved into its temperature and water $\delta^{18} \mathrm{O}$ components at ODP Site 1123 in the Southwest Pacific (Elderfield et al., 2010, 2012); however, the phasing inferred for the different components of the benthic $\delta^{18} \mathrm{O}$ in the SW Pacific signal does not necessarily apply to Site U1313. This is because Site U1313 is more affected by changes in the relative contribution of northern and southern-sourced water masses than Site 1123, and because of the long oceanic transit time of the water $\delta^{18} \mathrm{O}$ from the North 

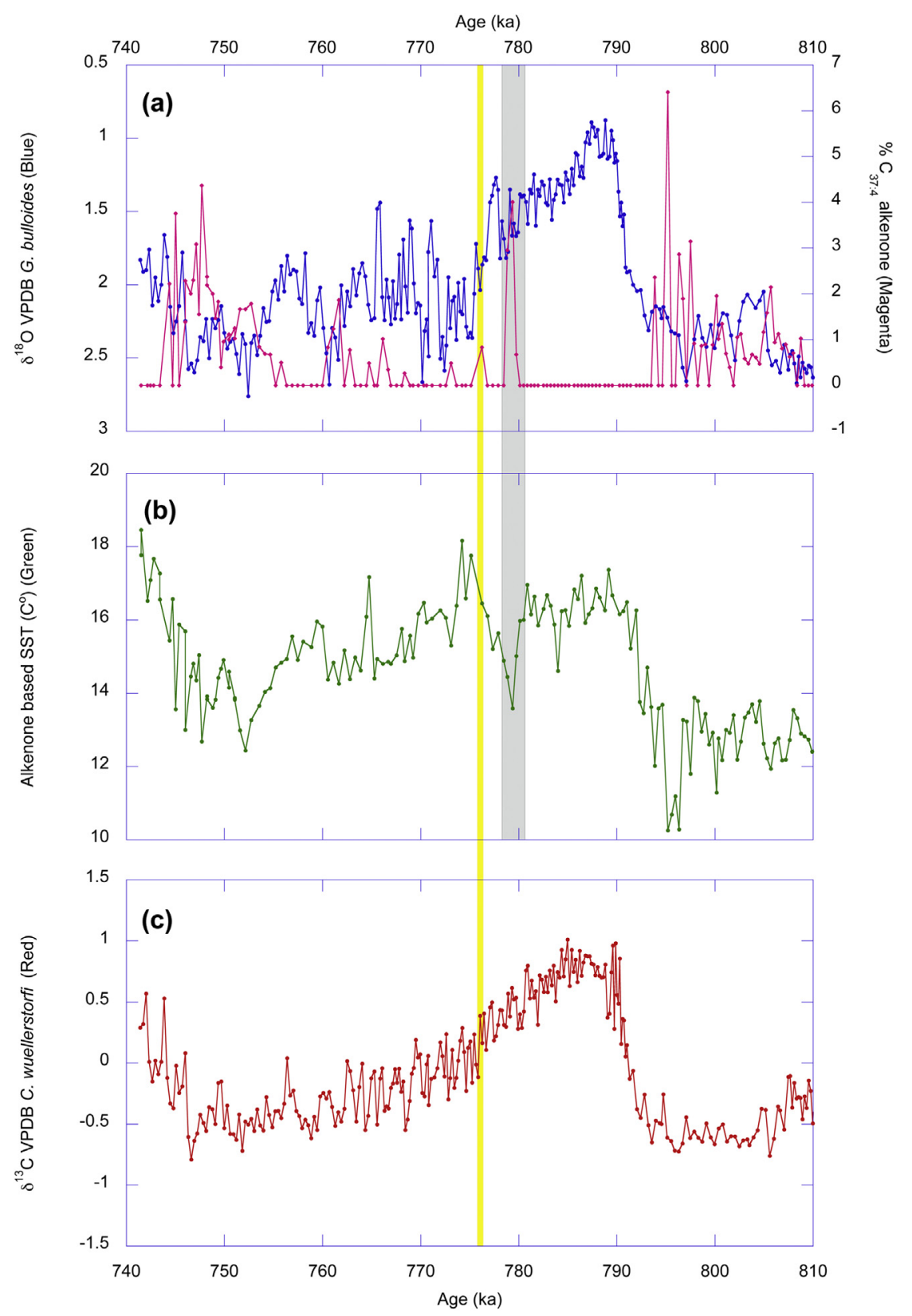

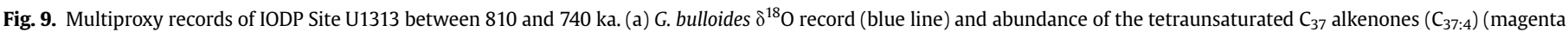

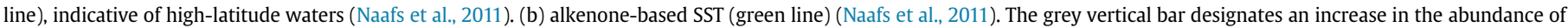

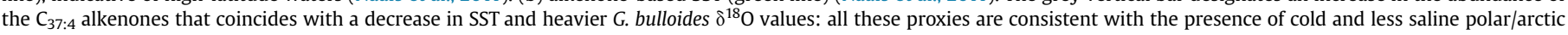

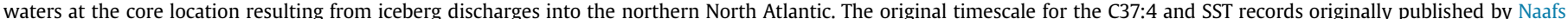

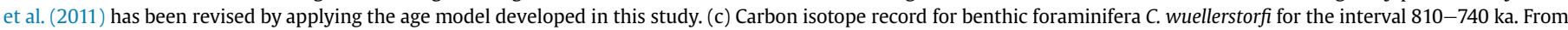

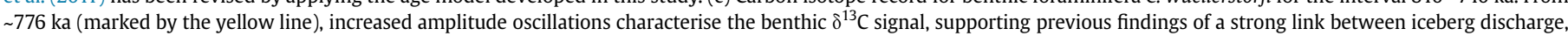

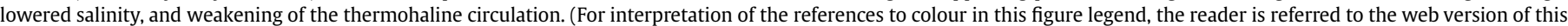
article.)

Atlantic to the deep SW Pacific (Skinner et al., 2003). We speculate that the phase relationship between the planktonic and benthic $\delta^{18} \mathrm{O}$ may indicate that the benthic $\delta^{18} \mathrm{O}$ is responding more immediately to the forcing than the surface $\delta^{18} \mathrm{O}$. If the $\delta^{18} \mathrm{O}$ variations reflect temperature differences in the water masses (most likely), then this phase relationship suggests that the temperature of deep-water in the Northern Atlantic Ocean changes somewhat ahead of the surface water temperature, and therefore that such sub-Milankovitch surface temperature changes in this part of the ocean are mainly initiated by changes elsewhere in the global ocean surface, and transferred to this part of the North Atlantic surface ocean by secondary processes such as changes in the position of the polar front. Another hypothesis would be that changes in the $\delta^{18} \mathrm{O}$ of the seawater itself resulting from ice volume changes at subMilankovitch periodicities are transferred to the North Atlantic surface only after a delay, but this seems harder to envisage.

Another complex climate proxy is the benthic $\delta^{13} \mathrm{C}$ signal, being affected by multiple parameters (e.g. ageing and mixing of water masses, temperature-dependent air-sea exchange, organic carbon sequestered on the continents and continental shelves, as well as long-term changes in the isotopic composition of rivers). Also in this specific case, each parameter has the potential to show a 


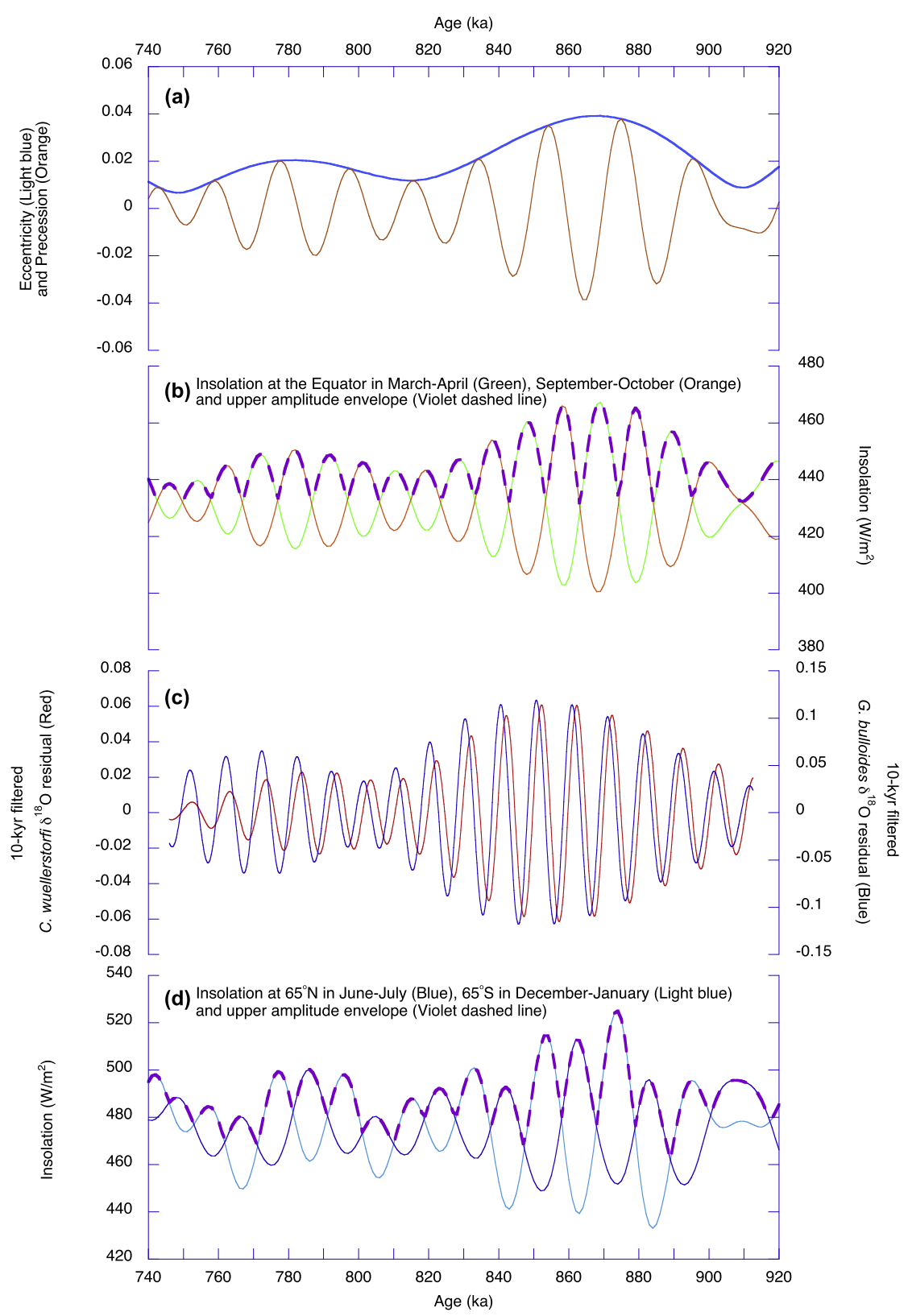

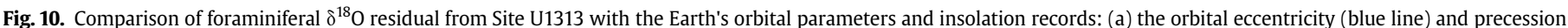

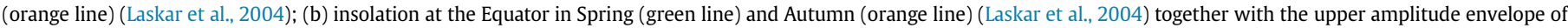

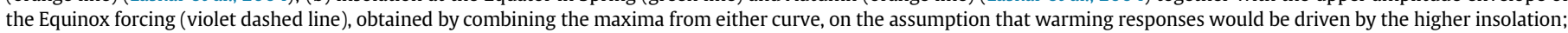

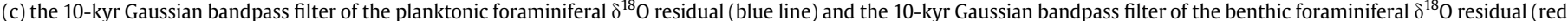

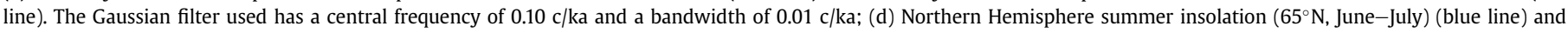

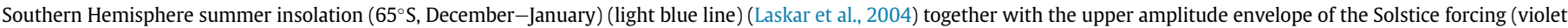
dashed line). (For interpretation of the references to colour in this figure legend, the reader is referred to the web version of this article.)

different phase relative to orbital forcing. Evidence of coupling between sea surface processes and deep water circulation may be inferred from concurrent shifts in the benthic $\delta^{13} \mathrm{C}$ and planktonic $\delta^{18} \mathrm{O}$ values. This is because, in the modern ocean, formation of NADW is contingent upon the temperature and salinity of the surface waters, and the extent to which these waters are cooled in winter at high latitudes; past changes in the North Atlantic surface circulation, having an influence on these parameters, could also have modified the rate of NADW production. Variability in the $11 \mathrm{kyr}$ band has been inferred in both the benthic $\delta^{13} \mathrm{C}$ and planktonic $\delta^{18} \mathrm{O}$ at Site U1313; however, no coherency is present despite the spectral peak in the half precession bandwidth (Fig. S5). This means that the lack of significant coherency between the benthic $\delta^{13} \mathrm{C}$ and planktonic $\delta^{18} \mathrm{O}$ residuals preclude a meaningful evaluation of the phase evolution in the interval analysed. Although these observations clearly indicate that surface- and deep-water records contain sub-orbital scale variation in the same band, they fail to unequivocally rule in a unique mechanism by which they were triggered.

\subsection{The role of the insolation}

The other important conclusion that can be drawn from the examination of the $11 \mathrm{kyr}$ part of the variance in the several signals is that even during periods of low eccentricity, low precession and low amplitude insolation variations, as occurred during MIS 19, the 


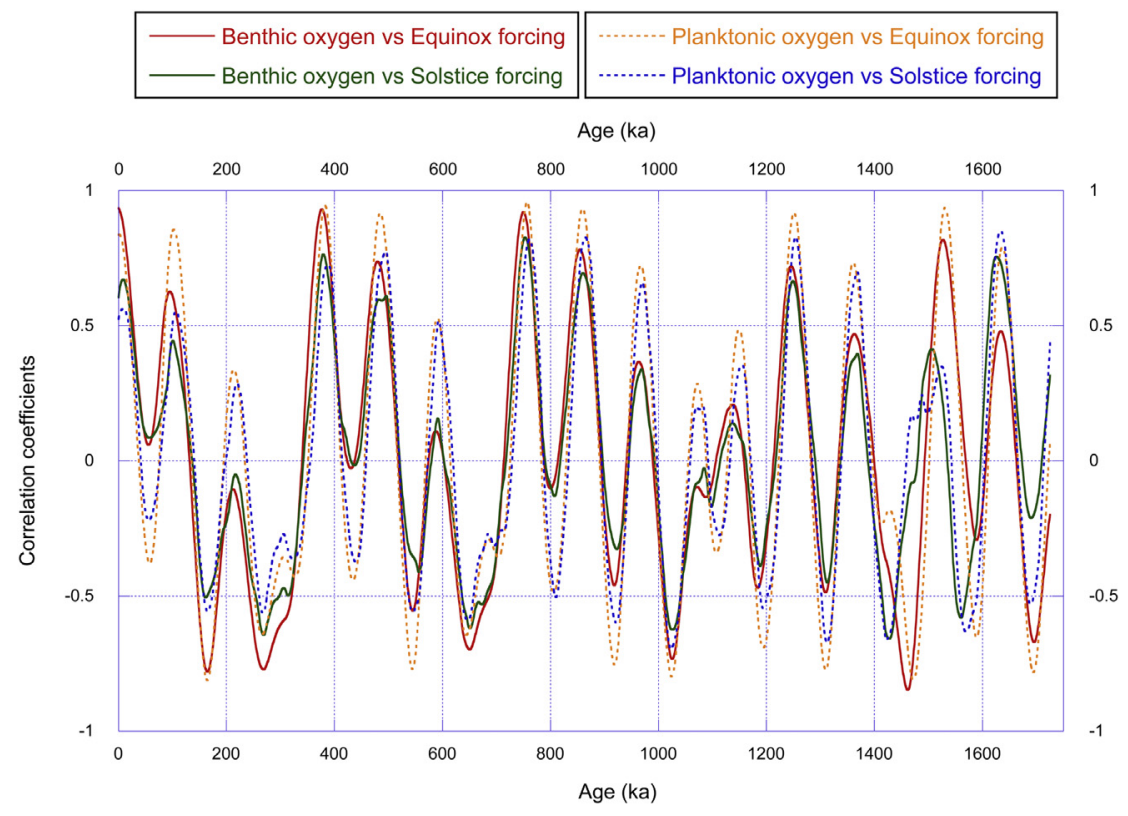

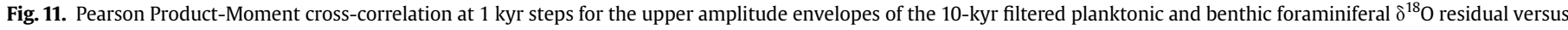

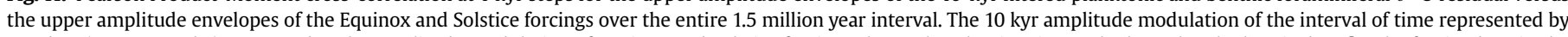

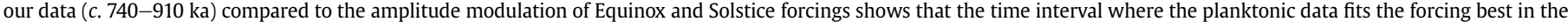

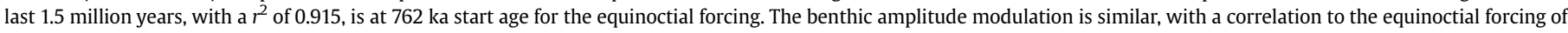
better than 0.849 starting at $755 \mathrm{ka}$. Both the planktonic and benthic response at $10 \mathrm{kyr}$ also make a good fit with the forcing at $380 \mathrm{ka}$ and $0 \mathrm{ka}$.

insolation appears to remain a plausible driver for millennial scale climate variability at Site U1313. Frequency analyses of different time series from deep-sea sediment cores covering the last $1.5 \mathrm{Ma}$ have recently suggested a complex picture of the relationship between climate response and astronomical forcing, where the entrained response of the climate system is intermittent, alternating intervals of 'capture' and 'escape' from the forcing (Clark et al., 2006). Although the system seems to jump from one state to the other at unpredictable times when stimulated by the lowfrequency forcing, this process seems to be governed by predictable background states. Nonlinearities can generate randomness, in the same way as a nonlinear climate response forced by the Milankovitch insolation could have determined the apparently random Dansgaard-Oescher cycles of the last $100 \mathrm{ka}$ (Rial and Yang, 2007; Braun et al., 2008). Our results do not preclude the possibility of such a complex scenario. That is, we propose here that insolation drives or paces rapid climate change directly and proportionally in the time slice analysed in this study, and our reconstruction appears to represent a period during which the climate system is 'captured' by the forcing. However, we are aware that these observations do not rule out the possibility that this is only part of a more complex picture characterised by an alternation of different states.

\section{Conclusions}

Reliable predictions of future global climate rely upon understanding its complex history. MIS 19, during the mid-Pleistocene transition, is a period during which the insolation appears comparable to the current orbital geometry: it is characterised by a subdued amplitude of precession as a consequence of the modulating effect of the $400 \mathrm{kyr}$ eccentricity cycle. The phasing between precession and obliquity is also very similar during the Holocene and MIS 19, making this marine isotopic stage a potential astronomical analogue for the Holocene and its future evolution if this remains governed by natural forcing (Loutre and Berger, 2000). In order to investigate whether the orbital insolation influenced climate variability in the millennial band and whether there are interactions between orbital and suborbital components of climate variability, we have reconstructed high-resolution records of surface- and deep-water hydrography from the North Atlantic Ocean during MIS 19. In agreement with our earlier study focussing on the older portion of the record (MIS 23-20), we propose that climate variations at sub-Milankovitch frequencies are amplitude and frequency modulated by the harmonics of the precession forcing. Benthic and planktonic stable isotope records from IODP Site U1313 document lower amplitude oscillations during MIS 19, as a result of the weak eccentricity-precession forcing; moreover, time series analysis illustrates that these variations still have a significant although weaker than during MIS 23-20 - concentration of spectral power centred on periods of $\sim 11 \mathrm{kyr}$, in both surface and deep water records, and $5.8 \mathrm{kyr}$ in the benthic oxygen signal. This timing is close to peaks expected from the second and fourth harmonics of the precessional component of the insolation forcing and we suggest that forcing from low latitudes is implicated in the origin of the harmonics of precession cycles observed at Site U1313. The precise mechanism by which the energy is transported into high latitudes away from equatorial regions is not easy to reconstruct from available proxy records, but experiments with Earth System models may provide useful insights into the way the climatic signal is transferred in the North Atlantic. On the other hand, although insolation seems to be the most plausible trigger for millennial scale variability, its extent depends also on the overall state of the climate system, as it occurred during the transition towards MIS 18 when large, cold excursions disrupted the surface waters due to instability of the Northern Hemisphere ice sheets.

In summary, our results suggest that the variables measured by proxies are replicated in cycles apparently paced by orbital changes, suggesting the climate system is to a significant extent understandable and deterministic, being contingent upon both forcing and previous history. If other climate records from different time intervals and locations confirm our conclusions - that is, the 
insolation determines, in the end, the timing and amplitude of rapid climate change - these results will have important implications in the context of future climate change. Cross-correlation coefficients between forcing and our proxy records show that during MIS 19 the orbital forcing at sub-Milankovitch periodicities, apparently echoed by the climatic response, is very close to that which we might expect at present and in the near future. This in turn implies the intriguing possibility that, as stated by Rial and Yang (2007), "since the insolation is certainly predictable, when climate models become reliable enough, abrupt climate change may also become predictable" to the extent that the behaviour of the climate system operates within the framework of its behaviour earlier in the recent geological record.

\section{Acknowledgements}

This work was supported by the EU through a Marie-Curie Reintegration grant (PERG-GA-2010-272134 - MILLEVARIABILI) to P.F. The research leading to these results has also received funding from the European Union's Seventh Framework Programme (FP7/ 2007-2013) under grant agreement no 243908, "Past4Future. Climate change - Learning from the past climate". This is Past4Future contribution no 80 .

This research used samples provided by the Integrated Ocean Drilling Program (IODP). We thank the crew of the JOIDES Resolution for enabling the Expedition 306 Scientists to recover such beautiful sediment cores. We are grateful to Walter Hale and Alex Wülbers of the IODP Bremen Core Repository at the MARUM Center for Marine Environmental Sciences for enabling us to conduct intensive sampling during our Expedition 306 post-cruise meeting, and to Joaquin Perona Moreno for assistance in the isotopic analyses. We are also thankful to David Hodell for stimulating discussion on age model development, and Graham Weedon for discussion of significance testing of periodic signals. We thank the editor Henning Bauch for his guidance, and two anonymous reviewers for their thorough, diligent and helpful evaluation of our study, which helped us to clarify the ideas in our preliminary manuscript.

\section{Appendix A. Supplementary data}

Supplementary data related to this article can be found at http:// dx.doi.org/10.1016/j.quascirev.2014.10.024.

\section{References}

Adhémar, J.A., 1842. Révolutions de la mer. Privately published, Paris.

Berger, A., 1988. Milankovitch theory and climate. Rev. Geophys. 26, 624-657. http://dx.doi.org/10.1029/RG026i004p00624.

Berger, A., Loutre, M.-F., Tricot, C., 1993. Insolation and Earth's orbital periods. J. Geophys. Res. Atmos. 98, 10341-10362. http://dx.doi.org/10.1029/93JD00222.

Berger, A., Loutre, M.F., Melice, J.L., 2006. Equatorial insolation: from precession harmonics to eccentricity frequencies. Clim. Past 2, 131-136. http://dx.doi.org/ 10.5194/cp-2-131-2006.

Billups, K., Rabideaux, N., Stoffel, J., 2011. Suborbital-scale surface and deep water records in the subtropical North Atlantic: implications on thermohaline overturn. Quat. Sci. Rev. 30, 2976-2987. http://dx.doi.org/10.1016 j.quascirev.2011.06.015.

Billups, K., Scheinwald, A., 2014. Origin of millennial-scale climate signals in the subtropical North Atlantic. Paleoceanography 29, 612-627. http://dx.doi.org/ 10.1002/2014PA002641.

Braun, H., Ditlevsen, P., Chialvo, D.R., 2008. Solar forced Dansgaard-Oeschger events and their phase relation with solar proxies. Geophys. Res. Lett. 35, L06703. http://dx.doi.org/10.1029/2008GL033414.

Clark, P.U., Archer, D., Pollard, D., Blum, J.D., Rial, J.A., Brovkin, V., Mix, A.C., Pisias, N.G., Roy, M., 2006. The middle Pleistocene transition: characteristics, mechanisms, and implications for long-term changes in atmospheric $\mathrm{pCO}_{2}$. Quat. Sci. Rev. 25, 3150-3184. http://dx.doi.org/10.1016/j.quascirev.2006.07.008.

Croll, J., 1867a. On the change in the obliquity of the ecliptic, its influence on the climate of the polar regions and on the level of the sea. Philos. Mag. 33, 426-445.
Croll, J., 1867b. On the eccentricity of the earth's orbit, and its physical relations to the glacial epoch. Philos. Mag. 33, 119-131.

Elderfield, H., Ferretti, P., Greaves, M., Crowhurst, S., McCave, I.N., Hodell, D., Piotrowski, A.M., 2012. Evolution of ocean temperature and ice volume through the mid-Pleistocene climate transition. Science 337, 704-709. http://dx.doi.org/ 10.1126/science.1221294.

Elderfield, H., Greaves, M., Barker, S., Hall, I.R., Tripati, A., Ferretti, P., Crowhurst, S., Booth, L., Daunt, C., 2010. A record of bottom water temperature and seawater $\delta^{18} \mathrm{O}$ for the Southern Ocean over the past $440 \mathrm{kyr}$ based on $\mathrm{Mg} / \mathrm{Ca}$ of benthic foraminiferal Uvigerina spp. Quat. Sci. Rev. 29, 160-169. http://dx.doi.org/ 10.1016/j.quascirev.2009.07.013.

Expedition 306 Scientists, 2006. Site U1313. In: Channell, J.E.T., Kanamatsu, T., Sato, T. Stein, R., Alvarez Zarikian, C.A., Malone, M.J., the Expedition 303/306 Scientists, Proc. IODP, 306, Integrated Ocean Drilling Program Management International, Inc., College Station TX, http://dx.doi.org/10.2204/iodp.proc.303306. 112.2006.

Ferretti, P., Crowhurst, S.J., Hall, M.A., Cacho, I., 2010. North Atlantic millennial-scale climate variability 910 to $790 \mathrm{ka}$ and the role of the equatorial insolation forcing. Earth Planet. Sci. Lett. 293, 28-41. http://dx.doi.org/10.1016/ j.epsl.2010.02.016.

Ferretti, P., Shackleton, N.J., Rio, D., Hall, M.A., 2005. Early-Middle Pleistocene deep circulation in the western subtropical Atlantic: southern Hemisphere modulation of the North Atlantic Ocean. In: Head, M.J., Gibbard, P.L. (Eds.), Early-Middle Pleistocene Transitions: the Land Ocean Evidence, vol. 247. The Geological Society, London, pp. 131-145.

Fratantoni, D.M., 2001. North Atlantic surface circulation during the 1990's observed with satellite-tracked drifters. J. Geophys. Res. 106, 22067-22093. http:/ dx.doi.org/10.1029/2000JC000730.

Ghil, M., Le Treut, H., 1981. A climate model with cryodynamics and geodynamics. J. Geophys. Res. Oceans 86, 5262-5270. http://dx.doi.org/10.1029/ JC086iC06p05262.

Hagelberg, T., Bond, G., De Menocal, P., 1994. Milankovitch band forcing of subMilankovitch climate variability during the Pleistocene. Paleoceanography 9 , 545-558. http://dx.doi.org/10.1029/94PA00443.

Hays, J.D., Imbrie, J., Shackleton, N.J., 1976. Variations in the Earth's orbit: pacemaker of the ice ages. Science 194, 1121-1132. http://dx.doi.org/10.1126/ science.194.4270.1121.

Hernández-Almeida, I., Sierro, F.J., Cacho, I., Flores, J.A., 2012. Impact of suborbital climate changes in the North Atlantic on ice sheet dynamics at the MidPleistocene transition. Paleoceanography 27, PA3214. http://dx.doi.org/ 10.1029/2011PA002209.

Howell, P., Pisias, N.J., Ballance, J., Baughman, J., Ochs, L., 2006. ARAND Time-Series Analysis Software. Brown University, Providence RI. Available at: http://www. ncdc.noaa.gov/paleo/softlib/arand/arand.html.

Jenkins, G.M., Watts, D.G., 1968. Spectral Analysis and its Applications. Holden-Day, San Francisco, 525 pp.

Kleiven, H.F., Hall, I.R., McCave, I.N., Knorr, G., Jansen, E., 2011. Coupled deep-water flow and climate variability in the Middle Pleistocene North Atlantic. Geology 39, 343-346. http://dx.doi.org/10.1130/G31651.1.

Laskar, J., Robutel, P., Joutel, F., Gastineau, M., Correia, A.C.M., Levrard, B., 2004. A long-term numerical solution for the insolation quantities of the Earth. Astron. Astrophys. 428, 261-285. http://dx.doi.org/10.1051/0004-6361:20041335.

Le Treut, H., Ghil, M., 1983. Orbital forcing, climatic interactions, and glaciation cycles. J. Geophys. Res. Oceans 88, 5167-5190. http://dx.doi.org/10.1029/ JC088iC09p05167.

Lisiecki, L.E., Raymo, M.E., 2005. A Pliocene-Pleistocene stack of 57 globally distributed benthic $\delta^{18} \mathrm{O}$ records. Paleoceanography 20, PA1003. http:// dx.doi.org/10.1029/2004PA001071.

Loutre, M.F., Berger, A., 2000. Future climatic changes: are we entering an exceptionally long interglacial? Clim. Change 46, 61-90. http://dx.doi.org/10.1023/A: 1005559827189.

Loutre, M.F., Berger, A., 2003. Marine Isotope Stage 11 as an analogue for the present interglacial. Glob. Planet. Change 36, 209-217. http://dx.doi.org/10.1016/S09218181(02)00186-8.

Maraun, D., Kurths, J., 2004. Cross wavelet analysis: significance testing and pitfalls. Nonlinear Process. Geophys. 11, 505-514. http://dx.doi.org/10.5194/npg-11505-2004.

Maraun, D., Kurths, J., Holschneider, M., 2007. Nonstationary Gaussian processes in wavelet domain: synthesis, estimation, and significance testing. Phys. Rev. E 75, 016707. http://dx.doi.org/10.1103/PhysRevE.75.016707.

McIntyre, A., Molfino, B., 1996. Forcing of Atlantic equatorial and subpolar millennial cycles by precession. Science 274, 1867-1870. http://dx.doi.org/10.1126/ science.274.5294.1867.

Naafs, B.D.A., Hefter, J., Acton, G., Haug, G.H., Martínez-Garcia, A., Pancost, R., Stein, R., 2012. Strengthening of North American dust sources during the late Pliocene (2.7 Ma). Earth Planet. Sci. Lett. 317-318, 8-19. http://dx.doi.org/ 10.1016/j.epsl.2011.11.026.

Naafs, B.D.A., Hefter, J., Ferretti, P., Stein, R., Haug, G.H., 2011. Sea surface temperatures did not control the first occurrence of Hudson Strait Heinrich Events during MIS 16. Paleoceanography 26, PA4201. http://dx.doi.org/10.1029/ 2011PA002135.

Naafs, B.D.A., Hefter, J., Stein, R., 2013. Millennial-scale ice rafting events and Hudson Strait Heinrich(-like) events during the late Pliocene and Pleistocene: a review. Quat. Sci. Rev. 80, 1-28. http://dx.doi.org/10.1016/ j.quascirev.2013.08.014. 
Niemitz, M.D., Billups, K., 2005. Millennial-scale variability in western tropical Atlantic surface ocean hydrography during the early Pliocene. Mar. Micropaleontol. 54, 155-166. http://dx.doi.org/10.1016/j.marmicro.2004.10.001.

Ortiz, J., Mix, A., Harris, S., O'Connell, S., 1999. Diffuse spectral reflectance as a proxy for percent carbonate content in North Atlantic sediments. Paleoceanography 14, 171-186. http://dx.doi.org/10.1029/1998PA900021.

Paillard, D.L., Labeyrie, L., Yiou, P., 1996. Macintosh program performs time-series analysis. EOS, Trans. Am. Geophys. Union 77, 379. http://dx.doi.org/10.1029/ 96EO00259.

Proistosescu, C., Huybers, P., Maloof, A.C., 2012. To tune or not to tune: detecting orbital variability in Oligo-Miocene climate records. Earth Planet. Sci. Lett. 325326, 100-107. http://dx.doi.org/10.1016/j.epsl.2012.01.022.

Raymo, M.E., Oppo, D.W., Flower, B.P., Hodell, D.A., McManus, J.F., Venz, K.A., Kleiven, K.F., McIntyre, K., 2004. Stability of North Atlantic water masses in face of pronounced climate variability during the Pleistocene. Paleoceanography 19 , PA2008. http://dx.doi.org/10.1029/2003PA000921.

Raymo, M.E., Ruddiman, W.F., Shackleton, N.J., Oppo, D.W., 1990. Evolution of Atlantic-Pacific $\delta^{13} \mathrm{C}$ gradients over the last 2.5 m.y. Earth Planet. Sci. Lett. 97, 353-368. http://dx.doi.org/10.1016/0012-821X(90)90051-X.

Rial, J.A. Yang, M., 2007. Is the frequency of abrupt climate change modulated by the orbital insolation?. In: Ocean Circulation: Mechanisms and Impacts - Past and Future Changes of Meridional Overturning Geophys. Monogr. Ser., vol. 173. AGU, Washington, DC, pp. 167-174.

Ruddiman, W.F., Raymo, M.E., Martinson, D.G., Clement, B.M., Backman, J., 1989. Pleistocene evolution: Northern hemisphere ice sheets and North Atlantic Ocean. Paleoceanography 4, 353-412. http://dx.doi.org/10.1029/ PA004i004p00353.

Rutherford, S., D'Hondt, S., 2000. Early onset and tropical forcing of 100,000-year Pleistocene glacial cycles. Nature 408, 72-75. http://dx.doi.org/10.1038/ 35040533.

Schulz, M., Mudelsee, M., 2002. REDFIT: estimating red-noise spectra directly from unevenly spaced paleoclimatic time series. Comput. Geosci. 28, 421-426. http://dx.doi.org/10.1016/S0098-3004(01)00044-9.

Shackleton, N.J., Berger, A., Peltier, W.R., 1990. An alternative astronomical calibration of the lower Pleistocene timescale based on ODP Site 677. Trans. R. Soc. Edinb. Earth Sci. 81, 251-261. http://dx.doi.org/10.1017/S0263593300020782.
Shackleton, N.J., Hall, M.A., Vincent, E., 2000. Phase relationships between millennial-scale events $64,000-24,000$ years ago. Paleoceanography 15 565-569. http://dx.doi.org/10.1029/2000PA000513.

Shackleton, N.J., Opdyke, N.D., 1973. Oxygen isotope and palaeomagnetic stratigraphy of equatorial Pacific Core V28-238: oxygen isotope temperatures and ice volumes on a $10^{5}$ year and $10^{6}$ year scale. J. Quat. Res. 3, 39-55. http:// dx.doi.org/10.1016/0033-5894(73)90052-5.

Short, D.A., Mengel, J.D., Crowley, T.J., Hyde, W.T., North, G.R., 1991. Filtering of Milankovitch cycles by Earth's geography. Quat. Res. 35, 157-173. http:// dx.doi.org/10.1016/0033-5894(91)90064-C.

Skinner, L.C., Shackleton, N.J., Elderfield, H., 2003. Millennial-scale variability of deep-water temperature and $\delta^{18} \mathrm{O}_{\mathrm{dw}}$ indicating deep water source variations in the Northeast Atlantic, 0-34 cal. ka BP. Geochem. Geophys. Geosyst. 4, 1098. http://dx.doi.org/10.1029/2003GC000585.

Stein, R., Kanamatsu, T., Alvarez-Zarikian, C., Higgins, S.M., Channell, J.E.T., Aboud, E., Ohno, M., Acton, G.D., Akimoto, K., Bailey, I., Bjørklund, K.R., Evans, H., Nielsen, S.H.H., Fang, N., Ferretti, P., Gruetzner, J., Guyodo, Y.J.B., Hagino, K., Harris, R., Hatakeda, K., Hefter, J., Judge, S.A., Kulbanek, D.K., Nanayama, F., Rashid, H., Sierro Sanchez, F.J. Voelker, A., Zhai, Q., 2006. North Atlantic paleoceanography: the last five million years. EOS, Trans. Am. Geophys. Union 87, 129-133. http://dx.doi.org/10.1029/ 2006E0130002.

Tzedakis, P.C., Channell, J.E.T., Hodell, D.A., Kleiven, H.F., Skinner, L.C., 2012. Determining the natural length of the current interglacial. Nat. Geosci. 5, 138-141. http://dx.doi.org/10.1038/ngeo1358.

Voelker, A.H.L., Rodrigues, T., Billups, K., Oppo, D., McManus, J., Stein, R., Hefter, J. Grimalt, J.O., 2010. Variations in mid-latitude North Atlantic surface wate properties during the mid-Brunhes (MIS 9-14) and their implications for the thermohaline circulation. Clim. Past 6, 531-552. http://dx.doi.org/10.5194/cp6-531-2010.

Wara, M.W., Ravelo, A.C., Revenaugh, J.S., 2000. The pacemaker always rings twice. Paleoceanography 15, 616-624. http://dx.doi.org/10.1029/2000PA000500.

Weirauch, D., Billups, K., Martin, P., 2008. Evolution of millennial-scale climate variability during the mid-Pleistocene. Paleoceanography 23, PA3216. http:/ dx.doi.org/10.1029/2007PA001584.

Wigley, T.M.L., 1976. Spectral analysis and the astronomical theory of climatic change. Nature 264, 629-631. http://dx.doi.org/10.1038/264629a0. 